\title{
Monoamines and Nitric Oxide Are Employed by Afferents Engaged in Midline Thalamic Regulation
}

\author{
Kazuyoshi Otake ${ }^{1,2}$ and David A. Ruggiero' ${ }^{13}$ \\ 'Laboratory of Neurobiology, Department of Neurology and Neuroscience, Cornell University Medical College, New \\ York, New York 10021, 2Department of Anatomy, Faculty of Medicine, Tokyo Medical and Dental University, Tokyo \\ 113 Japan, and ${ }^{3}$ Neurological Research Institute of Lubec, Lubec, Maine 04652
}

The neurochemical identities of afferents to the midline thalamus were investigated in chloral hydrate-anesthetized adult Sprague-Dawley rats. The retrograde tracers, FluoroGold or cholera toxin B subunit, were centered on the paraventricular thalamic nucleus (n.Pvt), a periventricular member of the diffuse thalamocortical projection system that is reciprocally linked with visceral areas of cerebral cortex and implicated in food intake and addictive behavior. Tissues were processed with antisera raised against 5-HT, the catecholamine-synthesizing enzymes, tyrosine hydroxylase or phenylethanolamine $\mathrm{N}$-methyltransferase or the cholinergic anabolic enzyme, ChAT. Serotonergic afferents principally derive from dorsal and median constituents of the mesopontine raphé. Previously unrecognized sources of catecholaminergic afferents were detected. Adrenergic afferents were traced to neurons in the $\mathrm{C}_{1}$ and $\mathrm{C}_{3}$ areas of rostral medullary reticular formation and periventricular gray, respectively, and the $\mathrm{C} 2$ area corresponding to the dorsal general viscerosensory field of nucleus tractus solitarii. Noradrenergic afferents arise principally from neurons in the locus ceruleus and A5 area. Dopaminergic projections to the n.Pvt derive from the A14, A13 and A11 cell groups in diencephalon.

Afferents presumed to generate nitric oxide (NO) as a diffusible membrane-permeant transcellular signal were detected by processing retrogradely labeled tissues histochemically for NADPH-diaphorase, a molecule associated with nitric oxide synthase. NO in the n.Pvt is generated predominantly by noncholinergic neurons in the lateral hypothalamic area and mesopontine tegmentum. In striking contrast, extensive interactions were predicted between $\mathrm{NO}$ and $\mathrm{ACh}$ in the central medial and other loci in the nondiscriminative thalamus. We conclude that the $n$.Pvt is a site of interaction of NO and monoaminergic afferents derived from nuclei implicated in sensory gating, regulation of electrocortical neural activity and behavior. Taken collectively, our data predict that the labile transcellular messenger NO may enable structurally differentiated subnuclei

Received Mar. 25, 1994; revised Aug. 17, 1994; accepted Aug. 30, 1994.

This work is supported by NIH Grants HL18974 and NS28200. We thank Mr. Muhammad Anwar for his expert technical assistance and Mr. Terence Ziegler for the excellent photography.

Correspondence should be addressed to Dr. David A. Ruggiero, Division of Neurobiology, Department of Neurology and Neuroscience, Cornell University Medical College, 411 East 69th Street, New York, NY 10021.

Copyright 1995 Society for Neuroscience 0270-6474/95/151891-21\$05.00/0 of the diffuse thalamocortical projection system to act in concert as a functionally unified unit.

[Key words: paraventricular thalamic nucleus, limbic system, afferent regulation, neurotransmitter, monoamine, neuromodulator, membrane-permeant transcellular signal, axonal transport, immunocytochemistry, rat]

The midline-intralaminar thalamus lies in a pivotal position between the sensorium and the cerebral cortex. Collectively, members of this complex comprise the nondiscriminative or diffuse thalamocortical projection system. Midline-intralaminar nuclei issue topographically organized projections to widespread areas of the cerebral cortex, predominantly to the frontal lobe (Herkenham, 1986; Bentivoglio et al., 1991; Berendse and Groenewegen, 1991, for reviews), and are targets of diverse afferent input conveyed by exteroceptive and visecral relay nuclei (Cornwall and Phillipson, 1988; Otake et al., 1993, 1994).

The nondiscriminative thalamus mediates cortical-evoked responses to peripheral polysensory stimulation (Albe-Fessard and Rougeul, 1958; Robertson and Thompson, 1973), or in response to repetitive low frequency stimulation, monosynaptic excitation of apical dendrites in deep and superficial layers of the cerebral cortex and desynchronization of the electroencephalogram (EEG) (Morison and Dempsey, 1942; see Macchi and Bentivoglio, 1986; Steriade and McCarley, 1990, for reviews). Complex stereotyped-behavioral responses have long been recognized as concomitants of midline or intralaminar thalamic stimulation although the neural networks are still unclear (Hunter and Jasper, 1949; Hess, 1957; Robinson and Mishkin, 1968).

Critical questions still unanswered are the precise functions of the constituent nuclei engaged in diffuse thalamosensory processing. Also unknown are the integrative actions of chemically specified afferents implicated in biasing cortical responsiveness and regulating state-dependent rhythmic oscillations that are coupled to behavior (Purpura et al., 1966; Purpura, 1972; Foote et al., 1983; see Steriade and Llinás, 1988; Steriade and McCarley, 1990, for reviews).

We have focused our studies on the periventricular component of the midline thalamus, a prominent though ill-defined member of the diffuse projection system implicated in conditioned addictive behavior (Brown et al., 1992). Myriad afferents to the thalamus have been identified including neurons which synthesize GABA (Montero and Zempel, 1985; Montero, 1987; Asanuma and Porter, 1990), monoamines (Swanson and Hartman, 1975; Consolazione et al., 1984; Westlund et al., 1990; Asanuma, 1992; Sim and Joseph, 1992), and ACh (Asanuma, 1989; Hallanger et al., 1987; Steriade et al., 1987), and, as recently 
suggested, a nitric oxide (NO) synthase (Bickford et al., 1993). The origins and postsynaptic targets of most chemically identified processes within the midline thalamus, however, have not been explored. As predicted by our axonal transport studies (Otake et al., 1993, 1994), afferents employing monoaminergic neurotransmitters and neuromodulators of behavior (Aston-Jones and Bloom, 1981; Arango et al., 1990, 1993) likely terminate in the midline thalamus. Of particular interest are sources of potential adrenergic projection from areas in the lower brainstem, for example, the nucleus tractus solitarii, involved in integrative viscerosensory processing (Ruggiero et al., 1994) and regulating electrocortical activity (Koella, 1977).

In the present investigation, combined retrograde transport and immunocytochemical methods were applied to determine the neurochemical identities of afferents which terminate in the dorsal portion of the midline thalamus (Otake et al., 1993, 1994). A structural basis was first sought for the roles ascribed to monoaminergic and cholinergic afferents in thalamosensory processing and regulating characteristic oscillatory rhythms of the EEG associated with periodic recurring stages of the sleep-wake cycle (see Jouvet, 1972; Steriade and Llinás, 1988, for reviews). The origins of cholinergic afferents to the midline thalamus, a locus implicated in feeding and cocaine abuse (Robinson and Mishkin, 1968; Brown et al., 1992), may be related to the effects of central cholinergic stimulation, via intracerebroventricular injection of carbachol, on locomotor and aggressive behaviors (Beleslin and Stevanovic-Denic, 1986).

We have also explored whether the gas NO might be employed as a labile transcellular messenger molecule by afferents terminating in the midline thalamus. Cholinergic neurons in the mesopontine tegmentum may generate NO (Vincent et al., 1983) and thus control state-dependent sensory gating functions of the thalamocortical projection system (Steriade and Llinás, 1988). We have focused our work on the paraventricular thalamic nucleus (n.Pvt) enriched in an NO synthase and recently classified as a constituent of the nondiscriminative thalamus and viscerallimbic system (Berendse and Groenewegen, 1991; Otake et al., 1994). This experimental series was designed based on recent compelling evidence that $\mathrm{NO}$ acts in the LGN, encouraging a functional state of activity conducive to wakefulness (Pape and Mager, 1992).

\section{Materials and Methods}

Data were obtained from seven male Sprague-Dawley rats (200-250 gm) anesthetized with chloral hydrate $(500 \mathrm{mg} / \mathrm{kg}$, i.p.). Unconjugated cholera toxin B subunit (CT-B, List Biological Lab.) or FluoroGold (FG, Fluorochrome Inc.) were employed as retrograde tracers. Procedures used to inject tracers were described elsewhere (Otake et al., 1994). In brief, $100 \mathrm{nl}$ deposits of $1 \%$ CT-B or $2 \%$ FG $(n=4)$ were placed stereotaxically in the dorsal midline thalamus through an opening in the calvarium created along the sagittal suture. After a survival period of 3 (for CT-B) or 5 (for FG) d, the animals were deeply anesthetized with sodium pentobarbital $(90-100 \mathrm{mg} / \mathrm{kg}$, i.p.) and perfused transcardially with physiological saline followed by $4 \%$ paraformaldehyde in $0.1 \mathrm{M}$ phosphate buffer. The entire brain was removed from each animal, blocked and immersed overnight at $4^{\circ} \mathrm{C}$ in $0.1 \mathrm{M}$ phosphate buffer containing $10 \%$ sucrose. Cryoprotected tissues were sectioned in the transverse plane at $35 \mu \mathrm{m}$ on a freezing microtome and collected in phosphate buffer. Sections from CT-B-injected animals were immunocytochemically processed with an antiserum raised against this tracer. Alternate retrogradely labeled tissue sections were processed immunocytochemically with antisera raised against serotonin, tyrosine hydroxylase (TH), phenylethanolamine $N$-methyltransferase (PNMT), or choline acetyltransferase (ChAT), or histochemically for NADPHdiaphorase (NADPH-d). Sections were mounted on gelatin-coated slides and air dried. Dually labeled cell bodies, that is, neurons containing both retrograde tracer and either 5-HT or synthetic enzymes, were mapped with the aid of a camera lucida attached to a Leitz microscope or photographed on TMAX 400 film (Kodak) with a Nikon FX microscope.

In three animals, serial transverse sections $(35 \mu \mathrm{m})$ of the diencephalon were stained for NADPH-d or processed immunocytochemically for ChAT. NAPDH-d positive or ChAT-immunoreactive neural elements were drawn with a camera lucida or photographed. Data were also available for analysis from cases used in previous studies of monoaminergic enzyme distribution in the CNS (Ruggiero et al, 1985)

Immunohistochemistry for $C T-B$. Nonspecific binding sites were blocked by preincubating free-floating sections in $1 \%$ bovine serum albumin (BSA) for $1 \mathrm{hr}$. Sections were subsequently incubated, overnight, in a CT-B antiserum raised in goat (List biological Lab.) (diluted 1:2000); for $45 \mathrm{~min}$ in biotinylated mouse anti-goat antibody $(1: 100$, Sigma) and $30 \mathrm{~min}$ in peroxidase-avidin complex (Vectastain Elite Kit, Vector Lab.) at room temperature. The tissues were treated with diaminobenzidine (DAB) and $\mathrm{H}_{2} \mathrm{O}_{2}$ to yield the immunoreaction product.

In order to dually label ChAT and CT-B on the same sections, tissues were first immunoprocessed for ChAT by the peroxidase-antiperoxidase
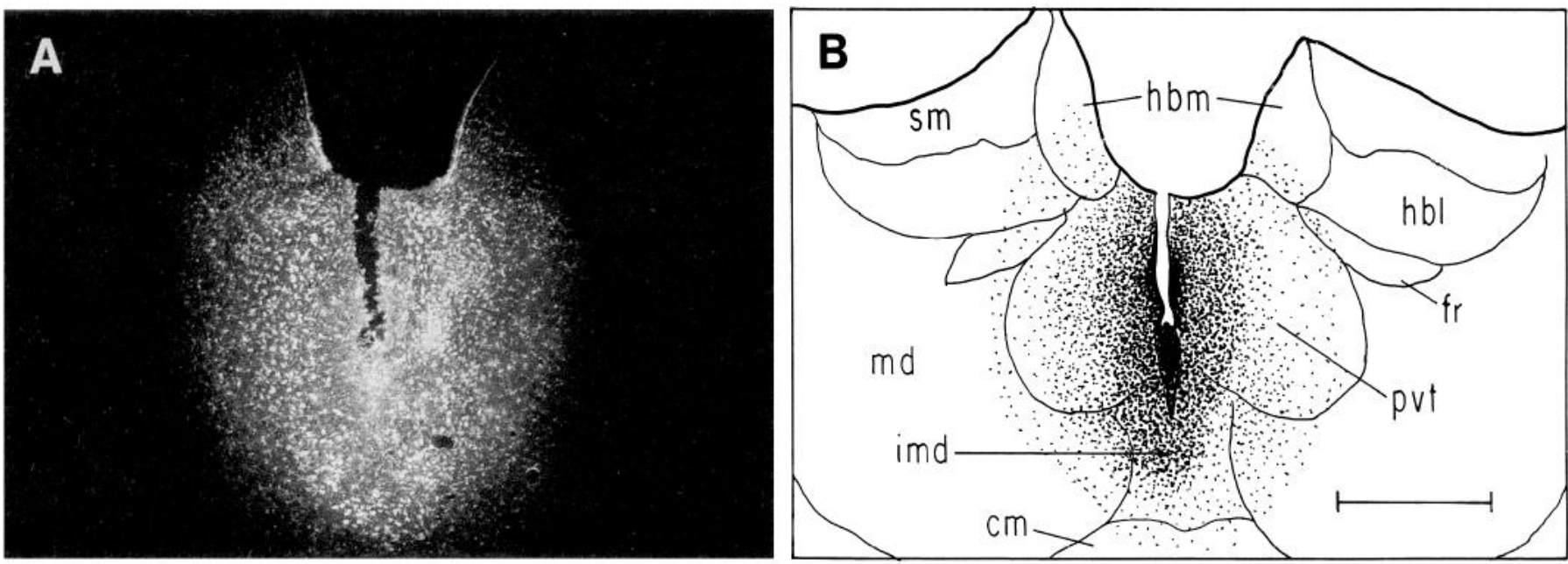

Figure 1. A, Photomicrograph demonstrates a representative injection site. FluoroGold was injected in the midline thalamus. A camera lucida drawing in $B$ shows the cytoarchitectural boundaries and spread of the tracer. The FluoroGold deposit is concentrated in the paraventricular thalamic nucleus $(p v t)$ and also encompasses the intermediodorsal $(i m d)$, central medial $(\mathrm{cm})$, and mediodorsal $(\mathrm{md})$ nuclei. Scale bar, $500 \mu \mathrm{m}$. 
(PAP) method as described below and then for CT-B by an indirect immunofluorescence method. PAP-treated sections were incubated in a goat antiserum raised against CT-B (1:200, Sigma), overnight, and in swine anti-goat IgG conjugated to fluorescein isothiocyanate (FITC, 1:100, Tago), overnight, at room temperature.

Immunohistochemistry for 5-HT, TH, and PNMT. Sections processed for CT-B or tissues from FG-injected animals were incubated overnight (16-20 hr), at room temperature in anti-5-HT (1:800, Incstar), anti-TH (1:200, Eugene Tech Labs.), or anti-PNMT (1:3000, Eugene Tech Labs.), and for $2 \mathrm{hr}$ in goat anti-rabbit IgG-rhodamine conjugate (1:100, Tago).

NADPH-d histochemistry. Retrogradely labeled tissues were reacted with $1.2 \mathrm{~mm} \beta$-NADPH (Sigma) and $0.24 \mathrm{~mm}$ nitroblue tetrazolium (Sigma) with $0.2 \%$ Triton $\mathrm{X}-100$ in $0.1 \mathrm{M}$ Tris $\mathrm{HCl}(\mathrm{pH} \mathrm{7.2)}$ for $15-25$ min at $37^{\circ} \mathrm{C}$, and then rinsed with cold phosphate-buffered saline.

Immunohistochemistry for ChAT. CT-B-immunolabeled sections were pretreated with $1 \%$ BSA and sequentially incubated in rat monoclonal antisera raised against ChAT (1:67, Boehringer-Mannheim), overnight, at $4^{\circ} \mathrm{C}$; for $1 \mathrm{hr}$ in rabbit anti-rat IgG (1:50, Accurate Chemicals) and $1 \mathrm{hr}$ in rat PAP (1:100, Sternberger-Meyer) at room temperature. Tissues were treated with DAB and immunoprocessed for CT-B with an indirect immunofluorescence method. Tissues from FG-injected animals were processed for ChAT with an immunofluorescence method. Sections were incubated overnight in rat anti-ChAT (1:67, BoehringerMannheim) at $4^{\circ} \mathrm{C}$, for $2 \mathrm{hr}$ in biotinylated goat anti-rat IgG (1:100, Amersham) at room temperature, and, overnight, in streptavidin R-phycoerythrin conjugate $\left(1: 100\right.$, Tago) at $4^{\circ} \mathrm{C}$.

\section{Results}

Injection sites and patterns of retrograde transport. Our principal objectives were to neurochemically identify sources of afferent projection to the midline thalamus.

Representative injection sites of FG and CT-B are shown in Figure 1 and in the inset of Figure 16, respectively. In each animal, the dense central core of the CT-B or FG deposit was centered on the paraventricular thalamic nucleus (n.Pvt) with variable spread to adjacent structures including the intermediodorsal and midline portion of the central medial nucleus. In some cases, the mediodorsal thalamic nucleus was encompassed by the outer margin of diffusion. There was no evidence of artifacts due to a potential interaction between the anti-goat IgG used to visualize the retrograde tracer CT-B and rhodaminelabeled goat anti-rabbit IgG used to visualize the catecholaminergic enzymes. The specificity of our data was verified by evidence that cells expressing rhodamine (TH- or PNMT-like) immunofluorescence were consistently confined to catecholaminergic cell groups. We did not observe evidence for crossreactivity. As expected, the majority of prethalamic afferent projection neurons retrogradely labeled for CT-B were consistently devoid of rhodamine fluorescence. Moreover, both FG- and CTB-injected animals showed identical retrograde transport patterns that appeared related to uptake of tracer from the midline thalamus. In support was the observation that the overall distributions of prethalamic afferents were comparable to data obtained with retrograde tracers and confirmed in anterograde transport studies (Cornwall and Phillipson, 1988; Otake et al., 1993, 1994)

Adrenergic afferents. On tissues processed by PNMT immunohistochemistry, the thalamic midline was confirmed as the preferential site of adrenergic-axon projection (Hökfelt et al, 1974, 1984a). PNMT-like-immunoreactive (lir) varicose fibers and punctate processes were heavily concentrated in the n.Pvt. A lightly immunolabeled field was seen in the rhomboid thalamic nucleus. Adjacent structures, mediodorsal, intermediodorsal and central medial thalamic nuclei and the habenular nuclei, were devoid of PNMT-immunoreaction product (Fig. $2 A$ ). The dense core of each injection site included in this report over-
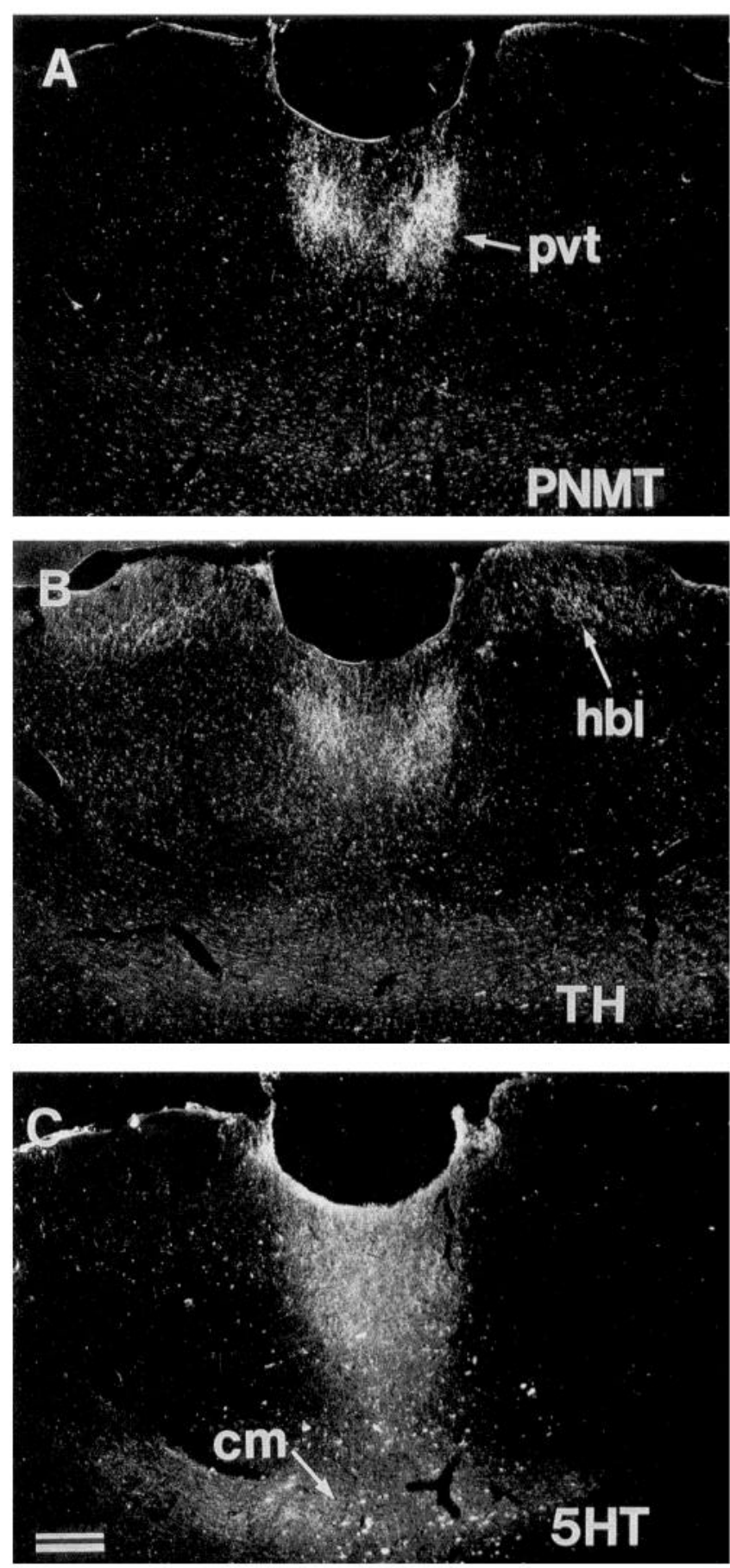

Figure 2. Epifluorescence photomicrographs show axonal fibers and terminal-like varicosities immunoreactive for PNMT $(A)$, TH $(B)$, and 5-HT $(C)$ in the dorsal thalamus. Scale bar, $200 \mu \mathrm{m}$.

lapped the area of dorsal midline showing the heaviest adrenergic, PNMT-positive, innervation.

Retrogradely labeled cell bodies containing PNMT reaction product were restricted to the medulla oblongata. Dually labeled cells were detected in an area of the ventrolateral medullary reticular formation corresponding to a portion of the $\mathrm{C} 1$ group and extending from the caudal pole of the facial nucleus to true obex (Figs. $3 F, G ; 4 A, B$ ). In the dorsal medulla, adrenergic prethalamic afferents were found in the dorsal subnucleus of the nucleus tractus solitarii (NTS), corresponding to the $\mathrm{C} 2$ cell 

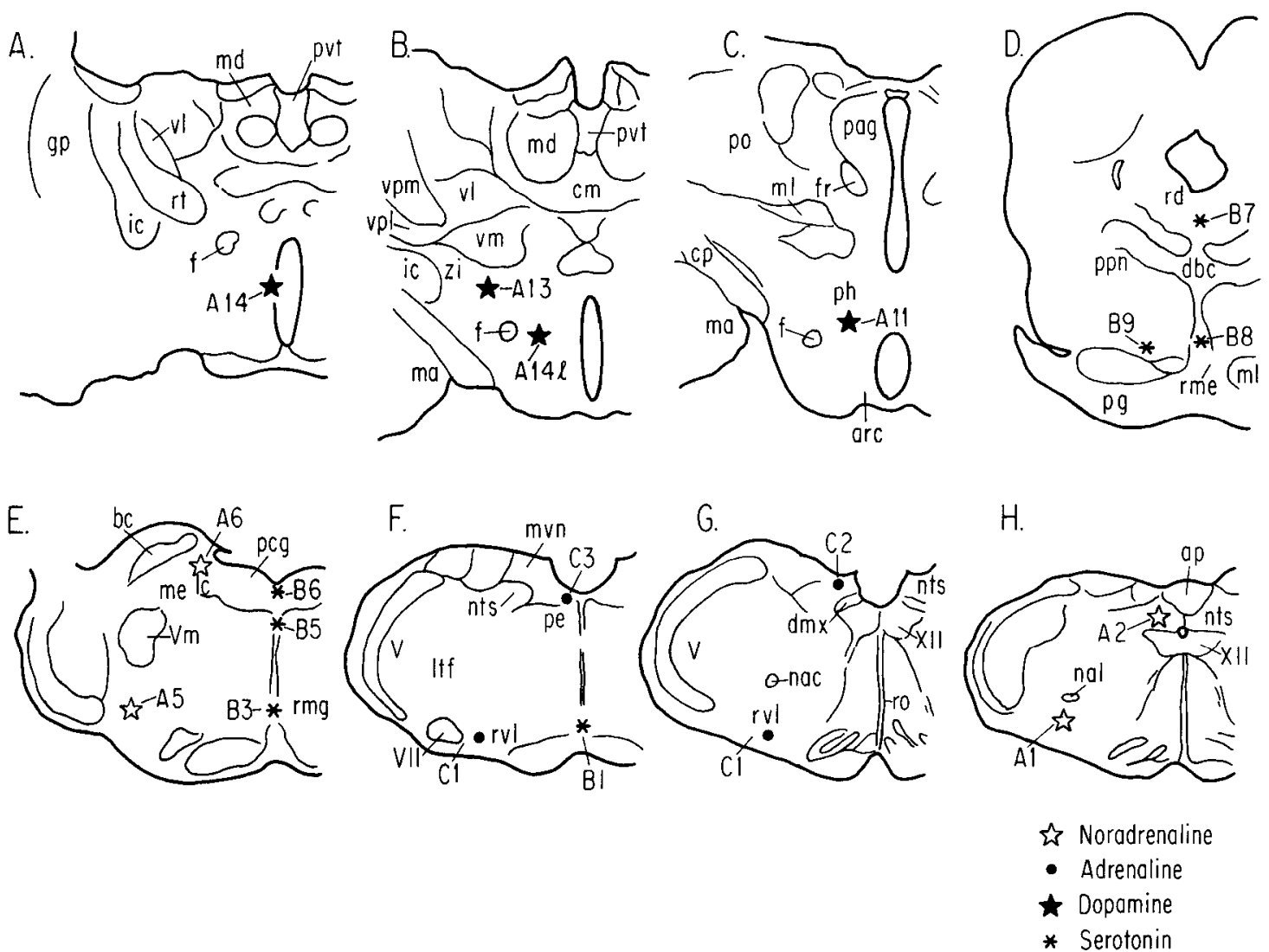

Figure 3. Summary diagram shows the location of monoaminergic afferents to the paraventricular thalamic nucleus in transverse section. Dually labeled cells were admixed with single labeled neurons in each monoaminergic cell group. The nomenclature is according to Hökfelt et al. (1984a,b) and Steinbusch (1981).

group (Figs. 3G, $4 E, F$ ). A third group of neurons containing both markers was present in a midline area of the rostral medulla, dorsal to the medial longitudinal fasciculus and corresponding to the $\mathrm{C} 3$ group (Figs. $3 F, 4 C, D$ ). These prethalamic afferents were located in the periventricular gray medial to the nucleus prepositus, and issued dendritic processes contacting ependyma lining the floor of the fourth ventricle, or extending medially into the dorsal medullary raphé.

Noradrenergic and dopaminergic afferents. Figure $2 B$ shows a field of TH-lir fibers and punctate terminal-type processes in the midline thalamus. These axons were densely distributed in the $n . P v t$ and epithalamus including lateral and medial habenular nuclei. Our tracer injections in the dorsal thalamus did not spread to the epithalamus.

In hindbrain, the principal sources of TH-lir prethalamic afferents were detected in the locus ceruleus (Figs. $3 E, 5 A, B$ ). Dually labeled cells were also seen in the A5 area of ventrolateral brainstem reticular formation (Figs. $3 E, 5 C, D$ ). In the dorsal medulla, dually labeled perikarya were also found in the commissural division of the NTS, caudal to the area postrema (Figs. $3 H, 5 E, F)$; corresponding to the A2 cell group. The majority of catecholaminergic neurons in this area contain TH and dopamine- $\beta$ hydroxylase, but not PNMT (Armstrong et al., 1982; Ruggiero et al., 1994). Prethalamic afferents from the A2 cell group are, therefore, presumed to be noradrenergic. In the ventrolateral medulla caudal to obex, most $\mathrm{TH}$-lir and prethalamic projection cells constituted separate populations. In the ventrolateral medulla the former, corresponding to the Al cell group, were skewed dorsolaterally; the latter, ventromedially and intermingled with a few dually labeled cells (Figs. $3 H, 5 G, H$ ).

In midbrain, no dually labeled cells were detected, although the distribution of prethalamic cells strongly overlapped TH-lir cells in the retrorubral area (A8) and ventral tegmental area of Tsai (A10).

In forebrain, a small number of dually labeled cells was detected in the periventricular hypothalamic nucleus (A14) and its lateral extension (A141, Hökfelt et al., 1984b), zona incerta (A13), and posterior hypothalamic area medial to the mammillothalamic tract (A11) (Figs. 3A-C, 6).

Serotonergic afferents. Serotonergic processes encompassed a broader area of the $n . P v t$ and were more widely distributed in the midline-intralaminar complex as compared to data from sections labeled for TH or PNMT (Fig. 2C). Tracer deposits were centered dorsally on the n.Pvt, and thus concentrated in the area of dense serotonergic innervation. The injections did not spread to the epithalamus which was also enriched in immunolabeled fibers. The distributions of retrogradely labeled cells were examined in areas harboring known serotonergic cell groups, B1 B9 (Steinbusch, 1981).

Dually labeled cells were detected mainly in the midbrain; predominantly within the nucleus raphe dorsalis (Figs. $3 D, 7 A$ $D$ ) and corresponding to the B7 cell group. Dually labeled cells were sparse in the nucleus raphé medianus (Fig. $7 E, F$ ) and vicinity of the medial lemniscus (Fig. 7G,H), which correspond to the B8 and B9 cell groups, respectively (Fig. $3 D$ ).

In pons (Fig. $3 E$ ), a few dually labeled cells were found in 

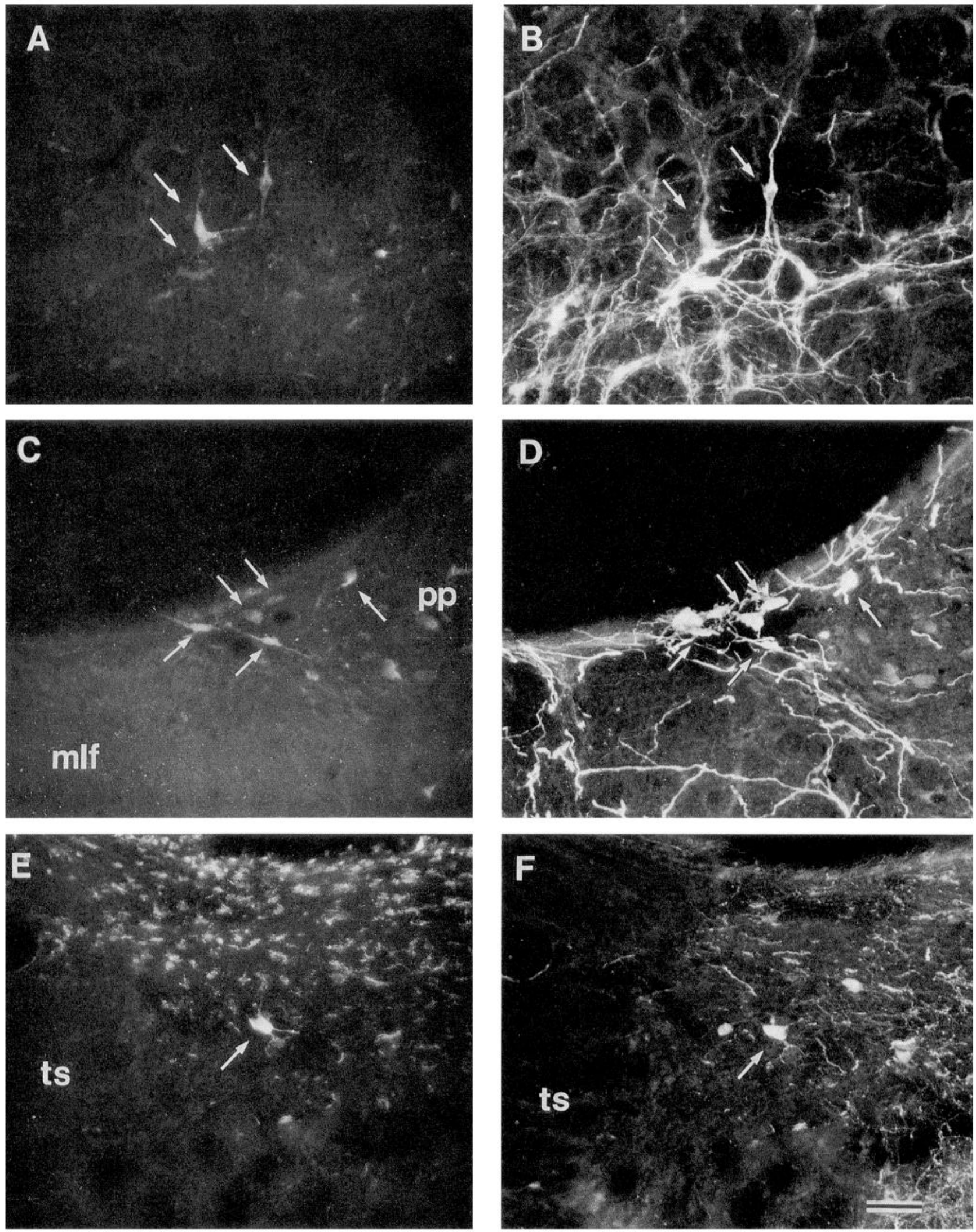

Figure 4. Photomicrographs show retrogradely labeled cells (left column) and PNMT-immunoreactive cells (right column) in the medulla. Arrows indicate dually labeled cells in the $\mathrm{C} 1(A, B), \mathrm{C} 3(C, D)$, and $\mathrm{C} 2(E, F)$ adrenergic cell groups. Scale bar, $50 \mu \mathrm{m}$. 

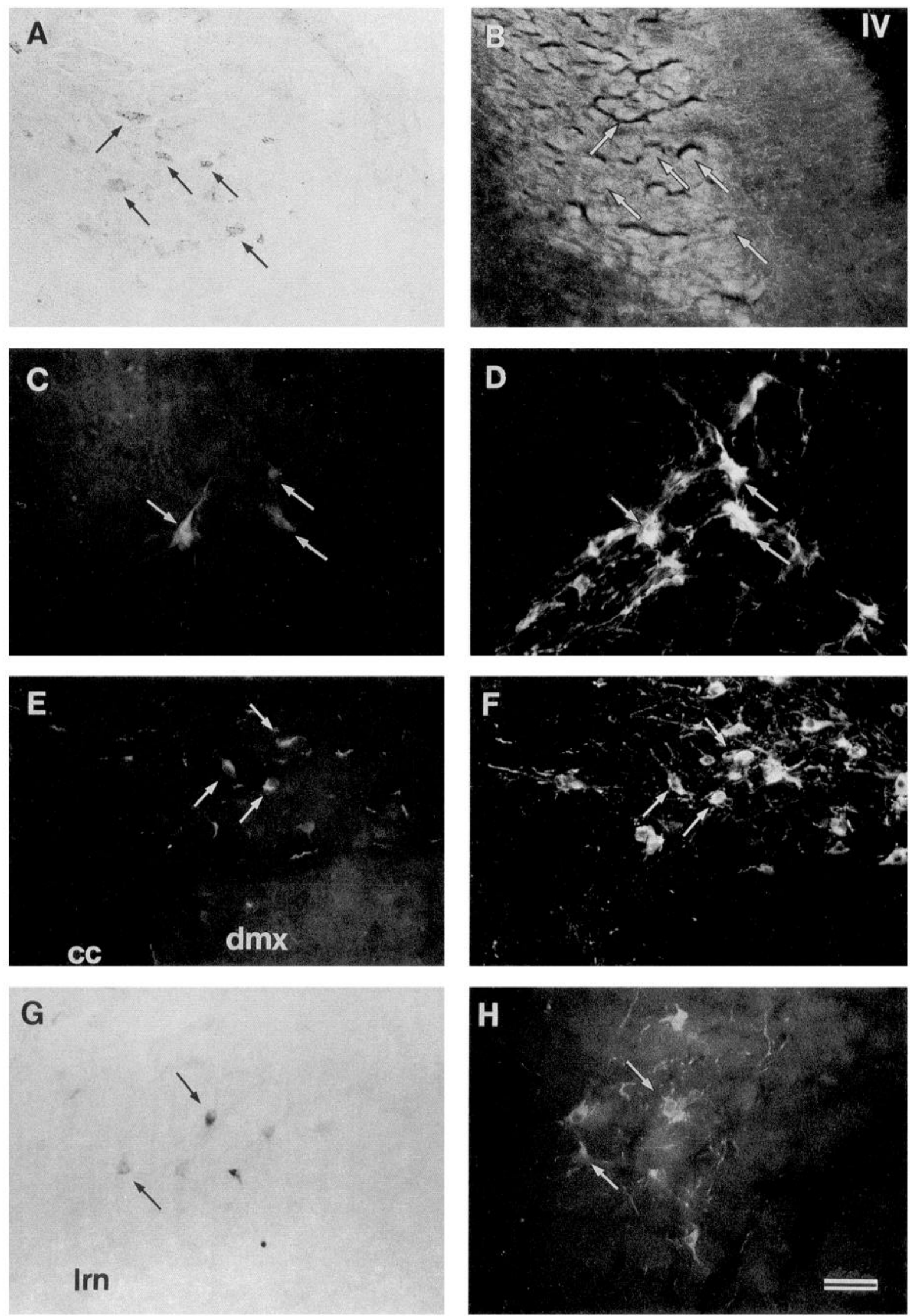

Figure 5. Photomicrographs show retrogradely labeled (left column) and TH-immunoreactive (right column) cell bodies on left ( $A-D, G, H)$ and right $(E, F)$ sides of lower brainstem. Arrows indicate dually labeled cells in the locus ceruleus, that is, A6 $(A, B), \mathrm{A} 5(C, D), \mathrm{A} 2(E, F)$, and A1 $(G, H)$ catecholamine areas of the lower brainstem. $I V$, Fourth ventricle. Scale bar, $50 \mu \mathrm{m}$. 

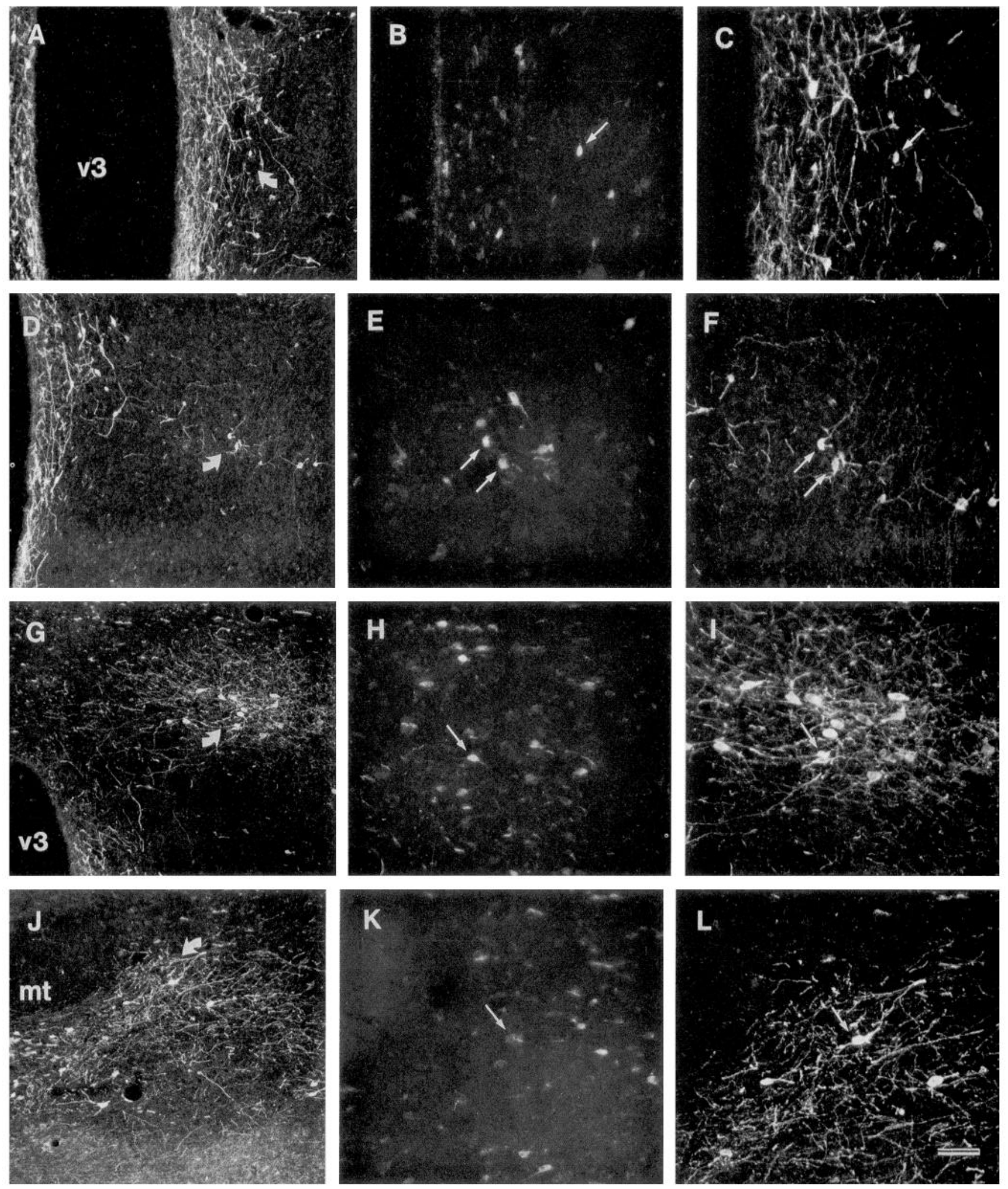

Figure 6. Photomicrographs show TH-immunoreactive cells $(A, C, D, F, G, I, J, L)$ and retrogradely labeled cells $(B, E, H, K)$ in diencephalon. Areas indicated with curved thick arrows in $A, D, G$, and $J$ are enlarged and shown in $B, C, E, F, H, I, K$, and $L$. Arrows indicate dually labeled cells in the A14 area $(A-C)$ and its lateral extension, A14l $(D-F), \mathrm{A} 13(G-I)$, and A11 areas $(J-L)$. Scale bar: $A, D, G, J, 100 \mu \mathrm{m} ; B, C, E, F, H$, $I, K, L, 50 \mu \mathrm{m}$. 

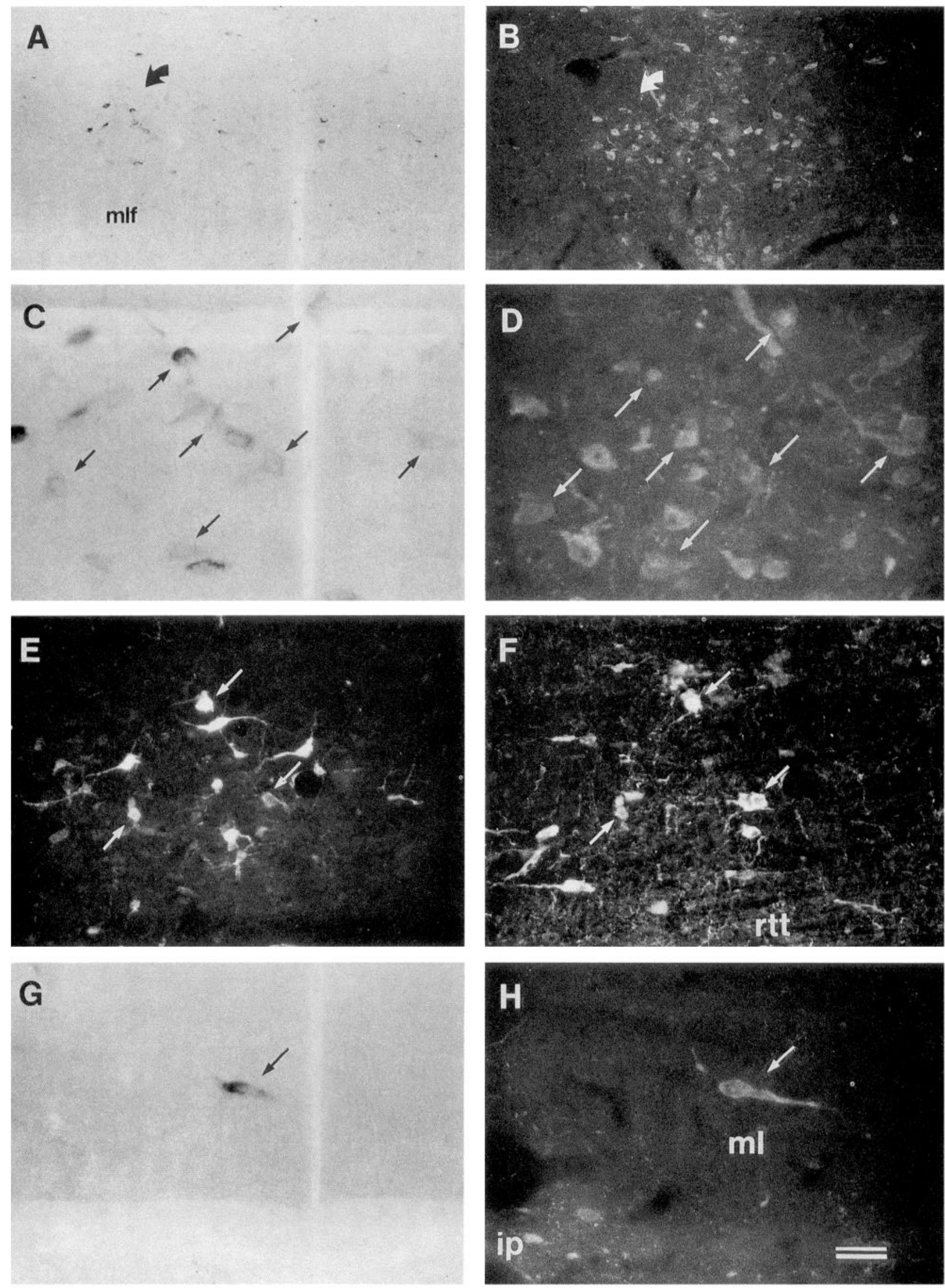

Figure 7. Photomicrographs show retrogradely labeled cells (left column) and 5-HT-immunoreactive cells (right column) in midbrain. Curved arrows in $A$ and $B$ indicate a portion of nucleus raphé dorsalis (B7 area) which is enlarged and shown in $C$ and $D$. Arrows indicate dually labeled cells in the $\mathrm{B} 7$ area $(C, D)$ and raphé medianus (B8 area) $(E, F)$ along the midline, and $\mathrm{B} 9$ area on right side $(G, H)$. Scale bar: $A$ and $B, 100 \mu \mathrm{m}$; $C-H, 50 \mu \mathrm{m}$. 

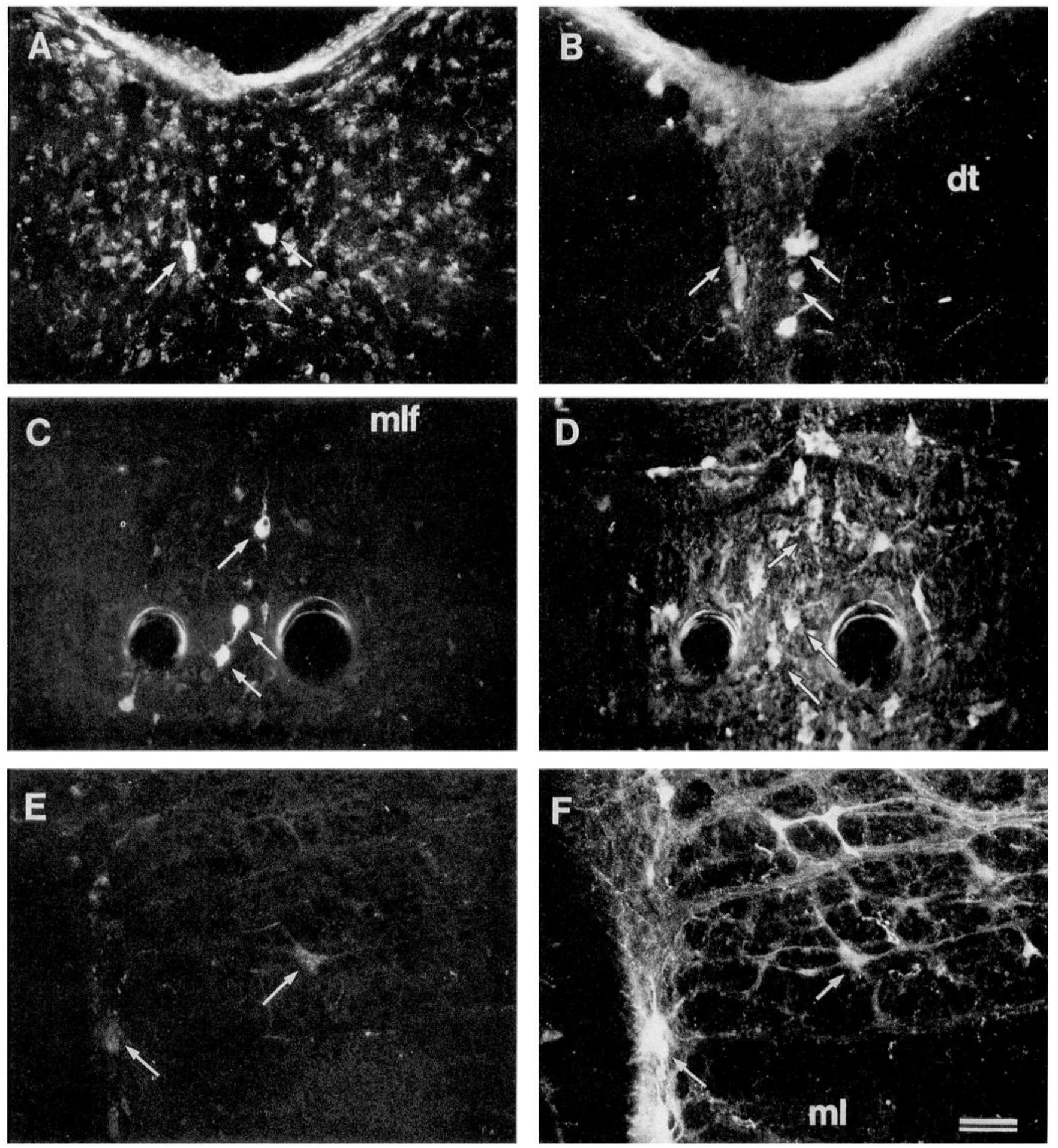

Figure 8. Photomicrographs show retrogradely labeled cells (left column) and 5-HT immunoreactive cells (right column) in pons. Arrows indicate dually labeled cells in the pontine dorsal raphé nucleus (B6 area) $(A, B)$, pontine raphé (B5 area) $(C, D)$, and raphé magnus (B3 area) $(E, F)$. Scale bar, $50 \mu \mathrm{m}$.

the B6 group corresponding to a caudal extension of nucleus raphé dorsalis (Fig. $8 A, B$ ), and in the nucleus raphé pontis, corresponding to the $\mathrm{B} 5$ group (Fig. $8 C, D$ ). No dually labeled cells were observed in the $\mathrm{B} 4$ group, corresponding to the midline area bordering the nucleus prepositus hypoglossi.

In medulla (Fig. $3 F$ ), the nuclei raphé magnus (B3 group) and raphé pallidus (B1 group) contained a small number of dually labeled cells (Fig. 8E,F). No dually labeled cells were found in the nucleus raphé obscurus (B2 group).

Distributions of NADPH-d and ChAT in the midline thalamus. The camera lucida drawings in Figures 9 and 10 illustrate the labeling patterns of NADPH-d and ChAT at two representative levels of the diencephalon. High to moderate concentrations of NADPH-d enzyme were detected in the neuropil of the midline 

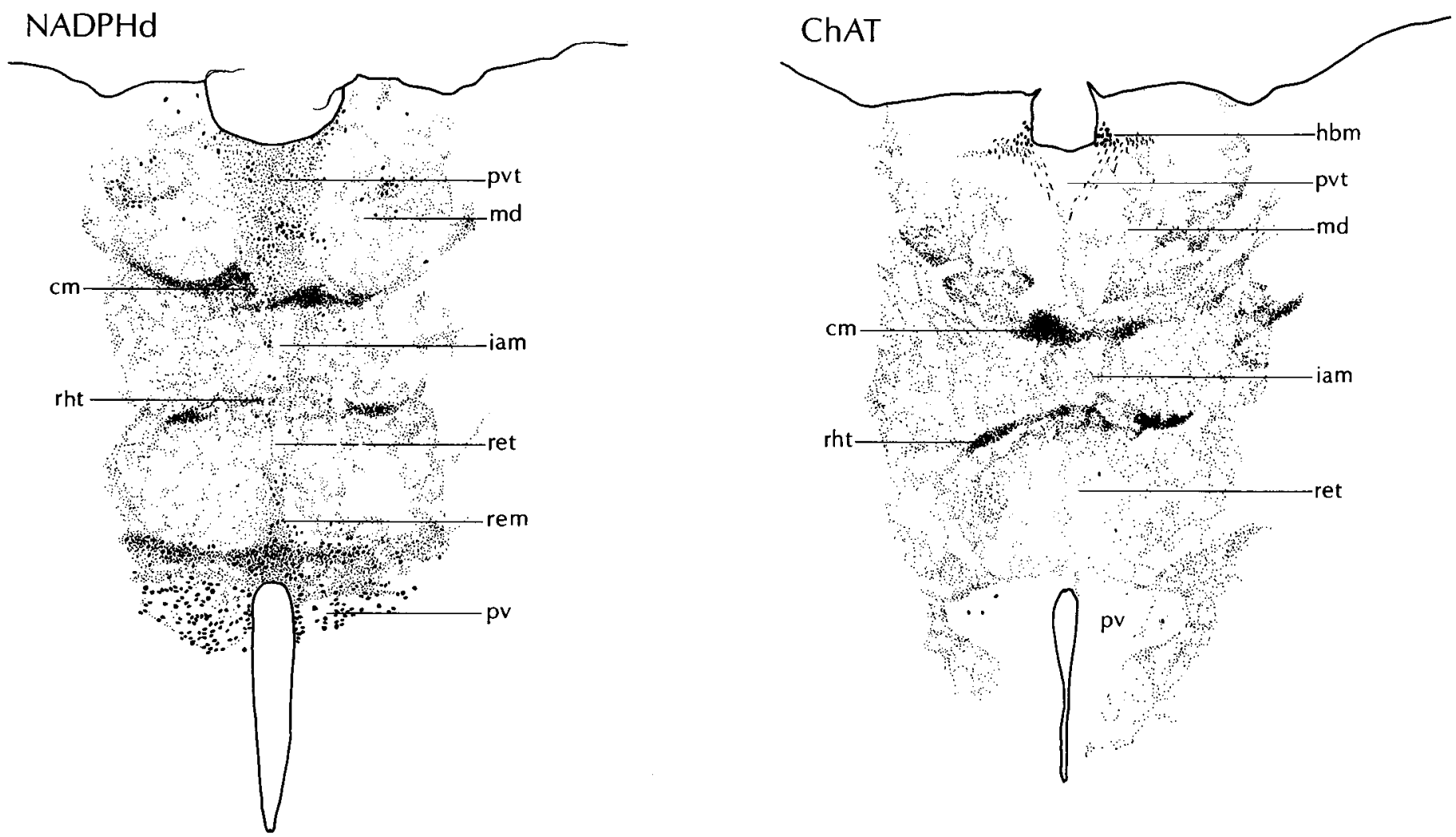

Figure 9. Camera lucida drawings of transverse sections through corresponding levels of diencephalon comparing distributions of processes staining for NADPH-d, a nitric oxide synthase and ChAT, the enzyme synthesizing ACh. Level is rostral to section illustrated in Figure 10. In the midlineintralaminar complex, both populations of afferent processes overlap in the central medial $(\mathrm{cm})$ and rhomboid $(r h t)$ thalamic nuclei. The paraventricular thalamic nucleus ( $p v t$ ) is enriched in NADPH-d although nearly devoid of punctate terminal-type processes.

and intralaminar thalamic nuclei (Figs. $11 A, C ; 12 A, B$ ). The n.Pvt was relatively heavily stained for NADPH-d in comparison to the weak histochemical reaction in the mediodorsal thalamic nucleus. NADPH-d in the n.Pvt extended ventrally along both sides of the midline and was bordered by a sparsely stained bilaterally symmetric field in the intermediodorsal nuclei. Caudally, at the level of the posterior hypothalamus, neuropil-staining for NADPH-d formed a well circumscribed bridge of processes extending between the n.Pvt and medial habenular nucleus (Fig. 11C). ChAT-immunopositive processes were sparse in the n.Pvt, although enriched in other nuclei of the midline-intralaminar complex (Figs. $11 D, 12 C, D$ ). The central medial and rhomboid nuclei showed overlapping distributional patterns of NADPH-d and ChAT. Cholinergic processes were detected in the fasciculus retroflexus neighboring a field of ChAT-lir cell bodies in the medial habenular nucleus. This labeling pattern was not observed on sections stained for NADPH-d (Fig. $11 \mathrm{~B}$ ). Cell bodies containing NADPH-d were present in the n.Pvt and subjacent divisions of the midlinc-intralaminar complex (Figs. 11B,C; 12B).

Cholinergic afferents. ChAT-lir prethalamic cells were detected exclusively in the mesopontine tegmentum. Few (0-2 cells/section) were dually labeled in the pedunculopontine (Ch5) and laterodorsal (Ch6) tegmental nuclei (Fig. 13). Other cholinergic cell groups (Ch1-Ch4) were not labeled by retrograde transport.

Nitric oxide afferents. The principal sources of NADPH-d in the midline thalamus were found in the hypothalamus and the mesopontine tegmentum.
Hypothalamic prethalamic afferents were detected in the lateral hypothalamic area, perifornical nucleus, dorsomedial nucleus, suprachiasmatic nucleus, and arcuate nucleus (Otake et al., 1994). Major NADPH-d-positive cell groups were present in the lateral hypothalamic area and parvocellular paraventricular hypothalamic nucleus. Moderate numbers of dually labeled cells were found in the rostral portion of the lateral hypothalamic area and a few occurred in the perifornical nucleus (Figs. 14C,D; 15).

In dorsal pons, retrogradely labeled cells were present in the laterodorsal tegmental nucleus, locus ceruleus, medial and lateral parabrachial nuclei and adjacent pontine reticular formation. Cells staining for NADPH-d were concentrated in the laterodorsal and pedunculopontine tegmental nuclei. Dually labeled cells were observed within the laterodorsal tegmental nucleus, where virtually all of the retrogradely labeled cells contained NADPH-d (Figs. 14A, $B$; 16). Small numbers of dually labeled cells were seen in the superior and dorsal subdivisions of the lateral parabrachial nucleus (Fig. 16).

In medulla, dually labeled cells were sparse and restricted to the medial and commissural subnuclei of the NTS.

\section{Discussion}

This study systematically identified throughout brain neurochemical substrates involved in afferent regulation of the midline thalamus. The mudline thalannus is a target of polysensory afferent input (Otake et al., 1994) and richly innervated by monoaminergic (catecholaminergic, serotonergic, histaminergic), cholinergic, and neuropeptidergic afferents (substance $\mathrm{P}$, neuro- 

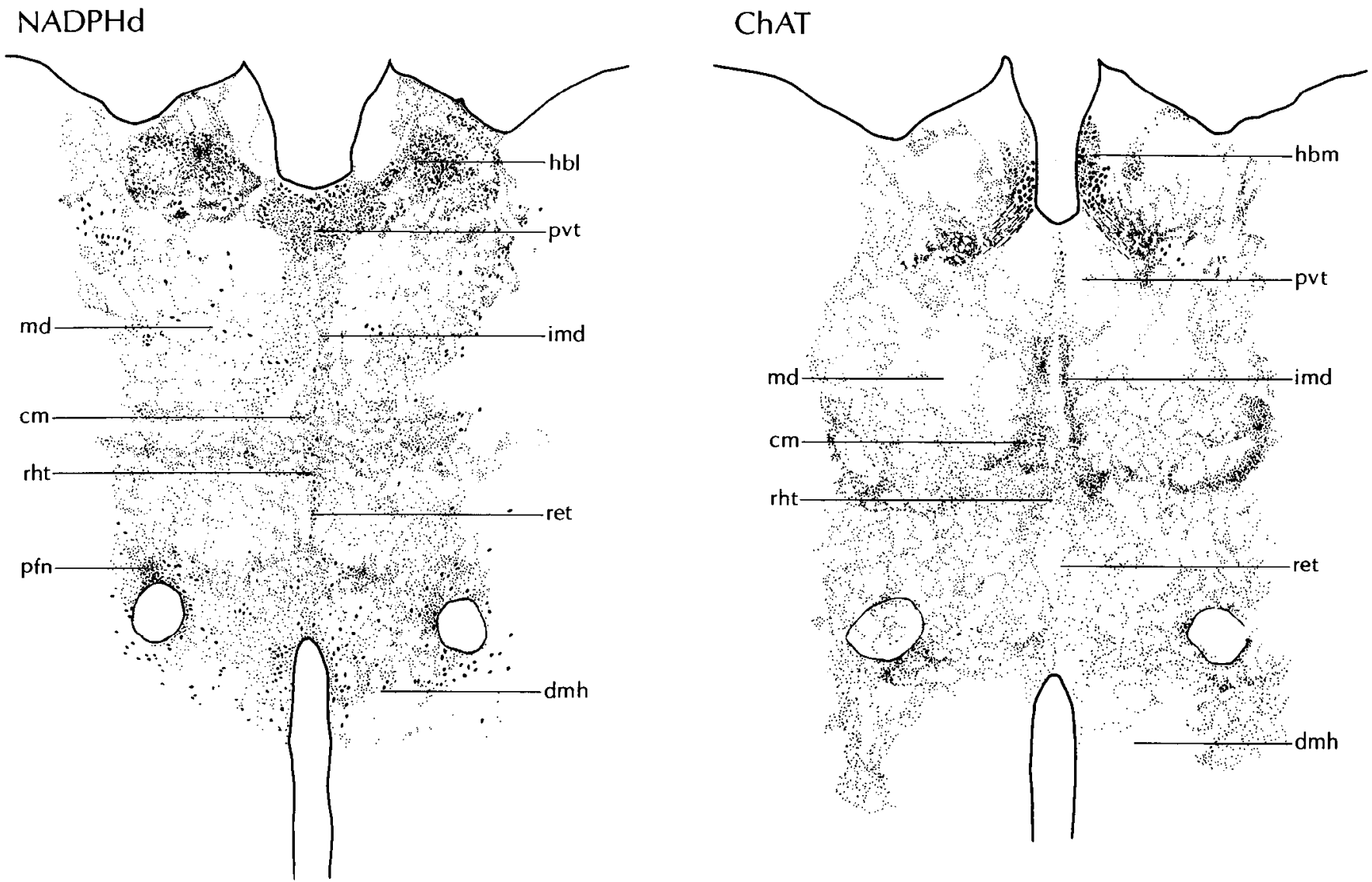

Figure 10. Camera lucida drawings of transverse tissue sections through the diencephalon. The paraventricular thalamic nucleus (n.Pvt) is characterized by a moderately high density of NADPH-d-positive processes differentiated from lower densities in ventral divisions of the midline thalamus and the mediodorsal thalamic nucleus. Cholinergic (ChAT immunoreactive) perikarya are heavily labeled in the medial habenular nucleus $(\mathrm{hbm})$; their axon processes form the fasciculus retroflexus. These cholinergic elements border the $\mathrm{n}$.Pvt which is nearly devoid of significant staining for ChAT. In contrast, NADPH-d and cholinergic processes overlap in other parts of the midline-intralaminar thalamus including the central medial and paracentral intralaminar nuclei, interanterodorsal and rhomboid midline thalamic nuclei.

peptide Y, cholecystokinin) (Bentivoglio et al., 1991, for review), and as recently shown, neurons containing a nitric oxide synthase (NOS) (Hope ct al., 1991). Prior to this report, the origins of most chemically identified processes within the midline thalamus were undefined.

Our work was focused on a dorsal periventricular constituent, the n.Pvt which projects selectively to visceral cortex and archistriatum (Bentivoglio et al., 1991; Berendse and Groenewegen, 1991), a member of a neural network subserving complex spontaneous and reactive behaviors (Robinson and Mishkin, 1968; Brown et al., 1992). A major contribution of the present report is neuroanatomical evidence that the midline thalamus may be modulated by complex interactions between several monoaminergic neurotransmitter projection systems and neurons capable of generating the gas nitric oxide (NO). The importance of our findings is underscored by the critical role of these neurochemicals in regulating electrocortical activity and behavior. Analysis of our neuroanatomical data follows.

\section{Catecholaminergic projections to the midline thalamus}

Our study provides direct evidence that catecholaminergic neurons in the lower brainstem constitute the principal origins of the norepinephrine and epinephrine innervation of the midline thalamus.

The major sources of norepinephrinergic afferents to the n.Pvt include the locus ceruleus and ventrolateral reticular formation. The following observations support this conclusion. First, TH lir neurons within the A6 and A5 areas were selectively labcled in our study by deposits of retrograde tracers centered on the n.Pvt. Second, the n.Pvt was characterized immunohistochemically by a dense circumscribed plexus of axons labeled for the rate-limiting catecholaminergic enzyme, TH (Hökfelt et al., $1984 \mathrm{~b}$ ) and the oxidative enzyme converting dopamine to norepinephrine, dopamine $\beta$-hydroxylase (DBH) (Swanson and Hartman, 1975).

Evidence obtained in our study of a direct pathway from the A5 area to the thalamus was suggested previously by glyoxylic acid fluorescence data (Lindvall et al., 1974). This observation is also consistent with neurochemical evidence that the medulla contributes to the levels of norepinephrine measured in the feline thalamus (Jones, 1978). The global projections of A6 neurons throughout the central nervous system encompassing widespread areas of cerebral cortex (Jones and Yang, 1985; Loughlin et al., 1986), and the predominantly descending fiber projections of the A5 area (Loewy et al., 1979; Westlund et al., 1981) suggest that prethalamic-norepinephrinergic afferents might arise as axon collaterals. Related findings predict that norepinephrinergic projections to the n.Pvt might arise as collaterals of other prethalamic afferents. A6 neurons also terminate in the reticular-GABAergic nucleus of the thalamus, where asymmetric axodendri- 

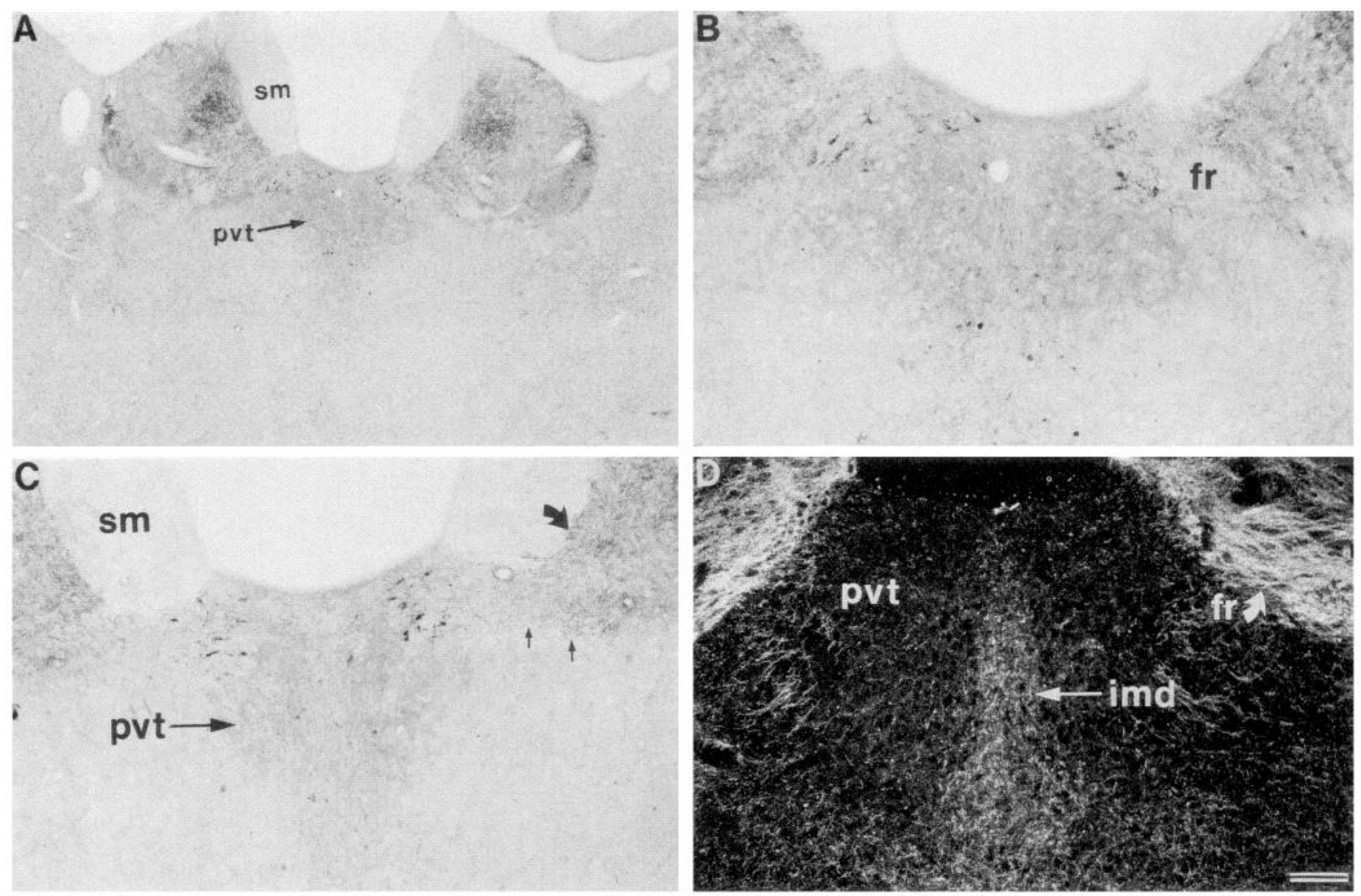

Figure 11. Photomicrographs of transverse sections cut through the diencephalon stained for the enzyme NADPH-d $(A-C)$ and immunolabeled for ChAT $(D)$. The neuropil of the n.Pvt is prominently stained for NADPH-d, but devoid of processes labeled for ChAT. Level A, shown under higher power magnification in $B$, is immediately rostral to the level shown in $C$ and equivalent to the level in the dark-field photograph in $D$. $D$, The intermediodorsal nucleus (imd) and fasciculus retroflexus $(f r)$, by comparison, are enriched in cholinergic processes and sparsely stained for NADPH-d. Also note in $B$ and $C$, a cluster of NADPH-d positive perikarya embedded in the fr and adjacent to n.Pvt, and, in $C$, a bridge of processes (small arrows) subjacent to the stria medullaris $(\mathrm{sm})$ and arching between the pvt and medial habenular nucleus (curved arrow). Scale bar: $A, 250 \mu \mathrm{m} ; B-D, 100 \mu \mathrm{m}$.

tic synapses are formed, en passant (Asanuma, 1992). Other thalamic nuclei including the anterior (Olschowka et al., 1981) and lateral geniculate (Papadopoulos and Parnavelos, 1990) nuclei are additional postsynaptic targets of norepinephrine projection fibers immunolabeled for DBH.

Dopaminergic afferents to the midline thalamus were previously traced to areas A8 and A10 in the midbrain (Takada et al., 1990). We were unable to confirm these projections. The discrepancy is likely due to subtle differences in the centers of our injection sites, a critical factor based on evidence that the dense central core of a retrograde tracer deposit constitutes the effective uptake site (Ruggiero et al., 1982). Thus, whereas our injections were centered on the dorsal midline, those of Takada et al. appeared to partly involve the lateral habenular nucleus, which was previously reported to receive afferents from the dopaminergic A10 group (Swanson, 1982). Our data indicate, to the contrary, that the principal source of dopamine in the n.Pvt arises from neurons in the hypothalamus. TH-positive neurons in the forebrain are well recognized as dopaminergic since all are also enriched in aromatic L-amino acid decarboxylase which catalyzes the decarboxylation of L-dopa to dopamine and devoid of DBH which converts dopamine to norepinephrine (Jaeger et al., 1984; Ruggiero et al., 1984, 1985) Evidence that TH-lir neu- rons were retrogradely labeled from the n.Pvt in the present study is consistent with histofluorescence evidence of a dopaminergic innervation of the n.Pvt (Lindvall et al., 1984). Analysis of data from all three studies gave the impression that the dorsal projection system may be organized topographically: medial (A11-14) versus lateral (A8, A10) dopamine cell systems, using fornix as the divide, perhaps selectively target loci located in respective mediolateral loci in the dorsal diencephalon.

Another novel finding in our study was evidence that the ClC3 areas in medulla constitute the principal sources of epinephrinergic projection to the midline thalamus. These observations extend previous evidence of a rich plexus of PNMT-lir axon processes in the n.Pvt, and of sparse labeling of the nucleus rhomboideus (Hökfelt et al., 1974, 1984a). The n.Pvt was, unequivocally, the target of the double-labeled neurons identified by us since our injection sites were centered on this midline thalamic nucleus and avoided the ventral constituent. Neighboring thalamic nuclei, the mediodorsal and intermediodorsal nuclei, and the epithalamus were devoid of PNMT-lir axons verifying the topographic specificity of the epinephrinergic projection. Epinephrinergic projections to the midline thalamus, perhaps, arise as axon collaterals of $\mathrm{C} 1$ premotor projections to the intermediolateral cell column (Ross et al., 1984; Ruggiero 

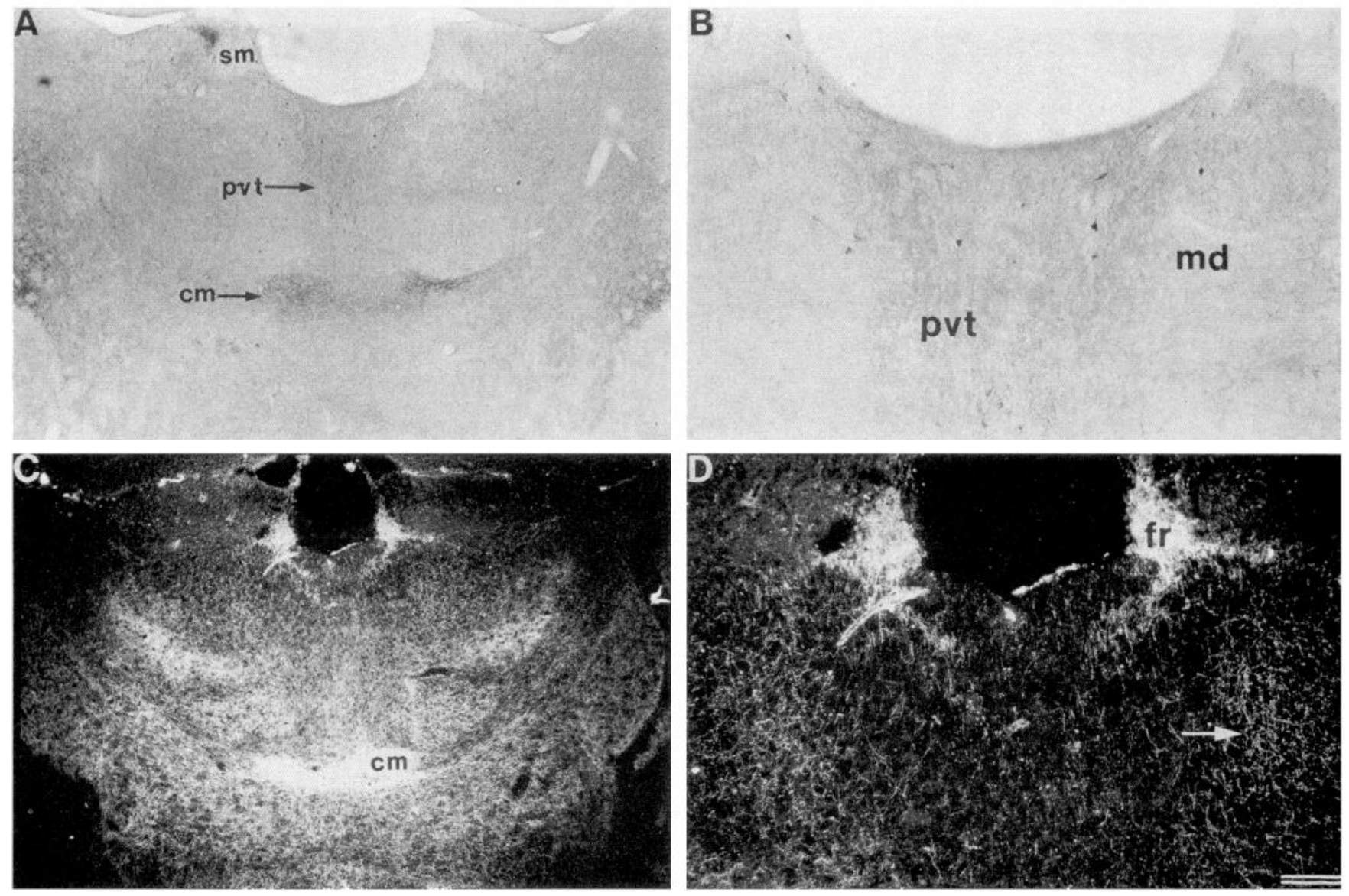

Figure 12. Photomicrographs of transverse sections through the dorsal diencephalon (level is rostral to those shown in Fig. 11). The principal observations reveal overlap of NADPH-d and ChAT in the neuropil of the central-medial nucleus (compare $A$ and $C$ ) and their mismatch in the n.Pvt. The n.Pvt although enriched in NADPH-d $(A, B)$ is devoid of processes containing ChAT-like immunoreactivity $(C, D)$. Level in $A$, shown under higher power magnification in $B$, is equivalent to level of sections in the dark-field photomicrographs in $C$ and as shown under higher power magnification in $D$. Scale bar: $A$ and $C 250 \mu \mathrm{m} ; B$ and $D, 100 \mu \mathrm{m}$.

et al., 1989), or as branches of the extensive C1-C3 innervation (Hökfelt et al., 1974, 1984a) of the lower brainstem and areas of the central gray and subcortical forebrain regulating sensory transmission (Gebhart, 1986; Willis, Jr., 1986) and involved in visceral-limbic function (Robinson and Mishkin, 1968; Ferssiwi et al., 1987; LeDoux, 1987; Brown et al., 1992). The present study also provided strong inferential evidence that certain prethalamic afferents may be targets of adrenergic innervation, for example, the central nucleus of the amygdala, neurons intercalated along amygdalofugal pathways-stria terminalis and ventral amygdalofugal bundle and the nucleus raphé dorsalis. This conclusion was justified by the impression that thamic afferent projection neurons were closely invested by high densities of PNMT-lir processes identical in morphology to those characterized ultrastructurally in other brain areas as terminal boutons (Van Bockstaelle and Pickel, 1993; K. Otake and D. A. Ruggiero, unpublished observation).

\section{Serotonergic projections to the midline thalamus}

Our study demonstrated that the n.Pvt is a key target of ascending projection from the nucleus raphé dorsalis. Our dual-labeling data confirm and extend previous immunocytochemical evidence of dense plexi of 5-HT-immunoreactive axons in the n.Pvt and other sites in the midline-intralaminar complex (Cropper et al., 1984).
Prior to our study, the origin of the serotonergic innervation of the midline thalamus was not explored with combined axonal transport immunocytochemical methods. Evidence of anterograde degeneration in the n.Pvt following electrolytic lesions of the nuclei raphé dorsalis and medianus (Conrad et al., 1974) was corroborated by our axonal transport data. Since lesions also interrupt axons en passant and provide no information related to the chemical identity of the ascending projection, our observations confirm and extend these data. Our observations complement autoradiographic studies of the pontine raphé (Conrad et al., 1974; Azmitia and Segal, 1974; Bobillier et al., 1976) and evidence of serotonergic projections from a dorsal locus in the nucleus raphé dorsalis and ventral periaqueductal gray to the central-medial and parafascicular nuclei, members of the nondiscriminative intralaminar thalamic projection system (Sim and Joseph, 1992). Serotonergic fiber pathways to the thalamus are differentially distributed, principally by way of the medial forebrain bundle, and also via the periventricular fiber system (Azmitia and Segal, 1978). Because the n.Pvt is intercalated within the periventricular fiber system, it has also been referred to as the nucleus periventricularis thalami (Cropper et al., 1984). Still unaddressed is whether afferents to diffuse thalamic nuclei are spatially segregated in the raphe or arise as collaterals, a question applicable to all sources of chemically identified processes. Widespread projections of the nucleus raphé dorsalis throughout 

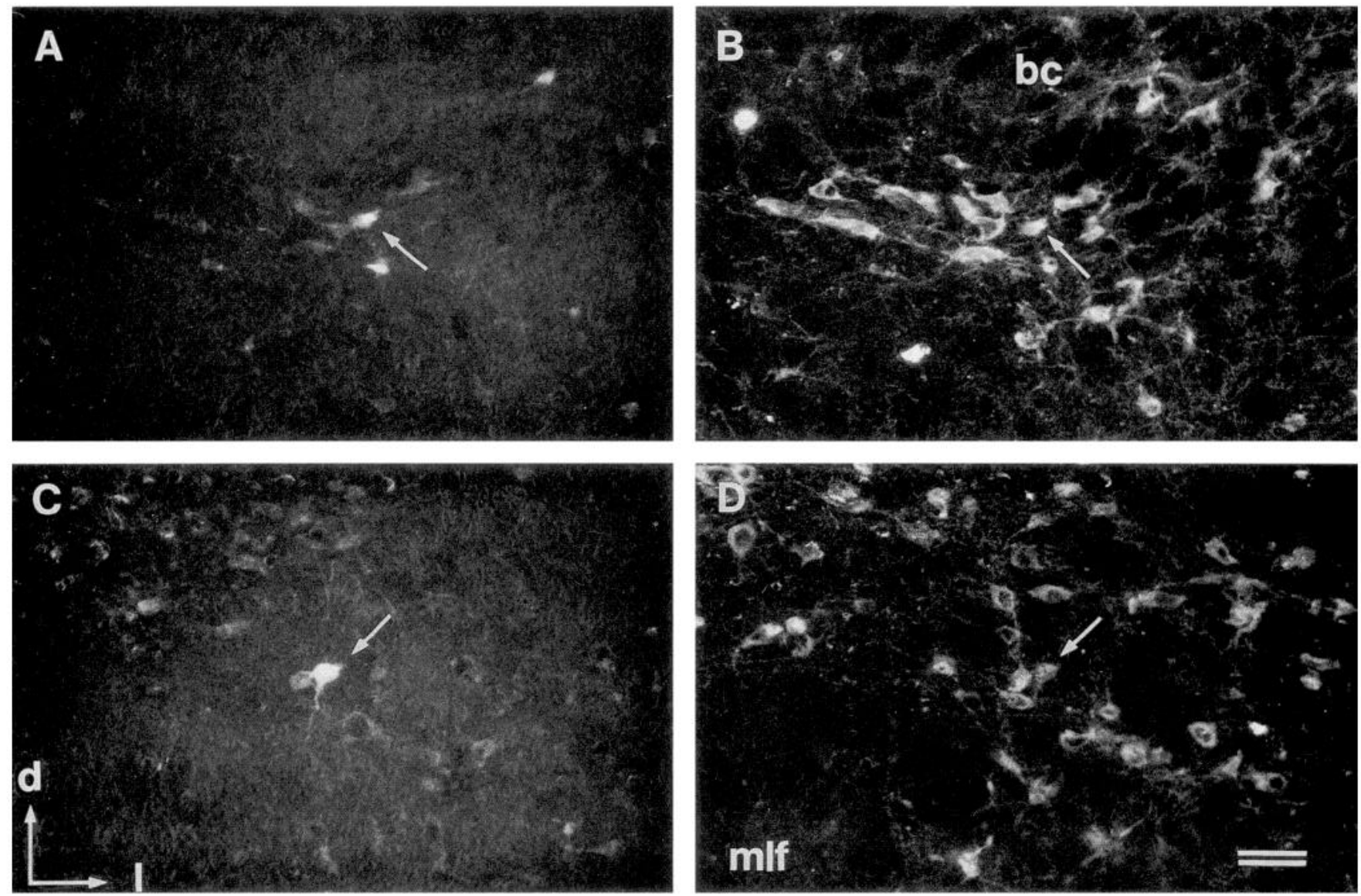

Figure 13. Photomicrographs show examples of retrogradely labeled (left column) and ChAT-immunoreactive (right column) cell bodies in mesopontine tegmentum. Arrows indicate dually labeled cells in pedunculopontine $(A, B)$ and laterodorsal $(C, D)$ tegmental nuclei. Directional arrows indicate dorsal $(d)$ and lateral $(l)$. Scale bar, $50 \mu \mathrm{m}$.

the CNS suggest that thalamic afferents may, in large part, arise as collaterals.

\section{Functional implications of monoaminergic afferents within the midline thalamus}

Monoaminergic afferents to the nonspecific thalamus may modulate the oscillatory behaviors of thalamosensory neurons contributing to state-dependent changes in the EEG.

Catecholamines. The locus ceruleus, the principal source of prethalamic norepinephrine projection to n.Pvt (this study) and cerebral cortex (Jones and Moore, 1977; Jones and Yang, 1985) is characterized, electrophysiologically, by behaviorally related neuronal activity patterns, for example, heightened during arousal and reduced in sleep (Hobson et al., 1975; Aston-Jones and Bloom, 1981). It is essential to verify, ultrastructurally, whether noradrenergic projections from the A6 and A5 areas terminate upon thalamosensory relay neurons in the n.Pvt and the precise connections with subsets of neurons projecting to the visceral cortex, amygdala, and/or nucleus accumbens (Berendse and Groenewegen, 1991). It is conceivable that these two sensory relay nuclei (Ricardo and Koh, 1977; Stornetta et al., 1987) modulate, by way of the periventricular division of the midline thalamus, signal flow through visceral-limbic networks.

The epinephrinergic afferent innervation of the n.Pvt by the C1-C3 areas of medullary reticular formation and periventricular gray is consistent with evidence that this midline subnu- cleus contains the highest concentration of PNMT in the thalamus. We conclude, therefore, that epinephrinergic neurons likely influence the outflow of the midline thalamus by a direct pathway to the n.Pvt and, perhaps, disynaptically. Disynaptic regulation by adrenergic neurons is predicted by intimate spatial relationships between PNMT-positive punctate fibers resembling terminals and retrogradely labeled prethalamic projection neurons (K. Otake and D. A. Ruggiero, unpublished observation).

Prethalamic cells in identical areas of medulla, C1-C3, were recently found to issue collaterals to the general viscerosensory division of NTS and dorsal motor nucleus of the vagus. These shared afferents were implicated in coupling state-dependent behavioral changes in cardiorespiratory or alimentary reflex functions with EEG rhythms associated with periodic-recurring phases of the sleep-wake-arousal continuum (Otake et al., 1994). Data from the present study predict that collaterals to the solitary nuclear complex and midline thalamus may, in part, employ epinephrine as a neuromodulator. More extensive branching patterns within epinephrinergic pathways likely exist since relatively small immunochemically identified cell groups give rise to far-ranging projections throughout the nervous system (Hökfelt et al., 1974, 1984a,b). The functional significance of the three spatially segregated circumscribed sources of prethalamic projection requires electrophysiological analysis. Evidence of a projection from the NTS (C2 area), or neighboring C3 periventricular/paramedian reticular area to the midline thalamus might 

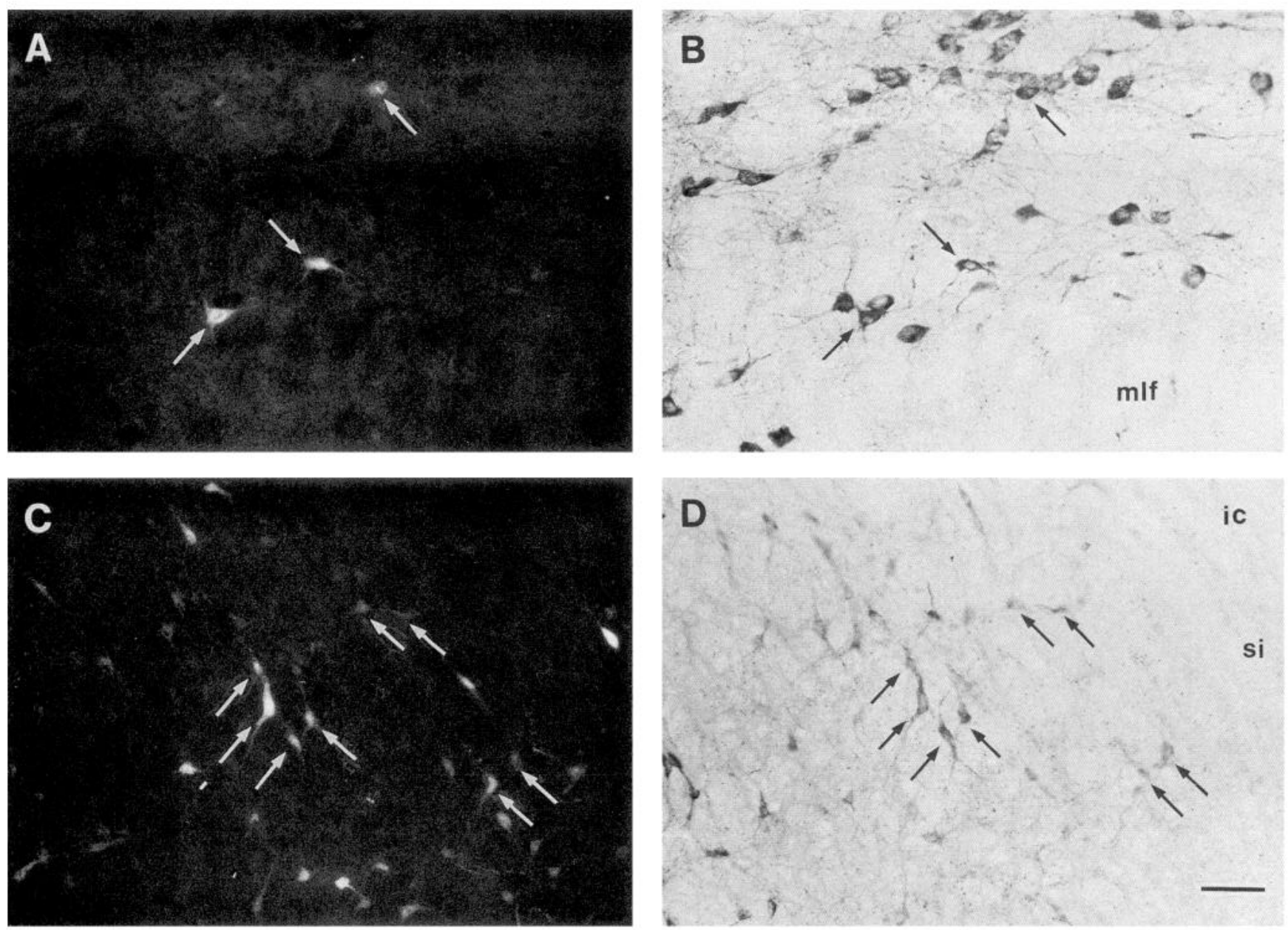

Figure 14. Photomicrographs show examples of FG-labeled (left column) and NADPH-d-containing cell bodies (right column) in the laterodorsal tegmental nucleus $(A, B)$ and the lateral hypothalamic area $(C, D)$. Arrows indicate dually labeled cells. Scale bar, $50 \mu \mathrm{m}$.

underlie a well recognized role of the NTS in sleep (Bonvallet and Block, 1961; Koella, 1977), or short-latency potentials in cerebral cortex evoked by peripheral visceral vagal afferent stimulation (Dell and Olson, 1951).

5-HT. The nucleus accumbens is a major subcortical target of the $n$.Pvt and implicated in goal-seeking behavior (Mogenson et al., 1980). Perhaps related is the aforementioned role of the midline thalamus in feeding. Serotonergic and TH-lir axon terminals in the core and shell of nucleus accumbens although intermingled as we have observed in n.Pvt lacked detectable synaptic contacts (Van Bockstaelle and Pickel, 1993). Evidence for convergence of serotonergic and TH-lir axons on the same archistriatal neurons, however, suggested an anatomical substrate for interactions between these two neurotransmitter systems. Similar convergent interactions are predicted by the extensive overlap of TH-lir and serotoninergic afferents identified in the n.Pvt.

5 -HT is thought to serve as a neuromodulator of neurons implicated in sensory processing, homeostasis, and behavior (see Azmitia, 1978; Weiss et al., 1978; Cropper et al., 1984, for additional references). The role of the serotonergic projection to the nondiscriminative thalamus might be related to evidence that the cells of origin in the raphe and projection fields in forebrain are responsive to peripheral noxious stimulation and contribute to a neural network for analgesia (see Sim and Joseph, 1992, for references). Our demonstration of a direct, albeit weak, path- way from the B3 area to the thalamus was unexpected yet concordant with evidence that neurons in the nucleus raphé magnus principally contribute to the descending pain control system (Fields and Anderson, 1978). The antinociceptive functions attributed to the nucleus raphé dorsalis (Dafney et al. 1990; PrietoGomez et al., 1989), and the hypothesized role of these neurons in coordinating the overall behavioral (arousal) response to pain require a more extensive analysis. A role of 5-HT in modulating arousal and feeding in invertebrates (Rosen et al., 1989) is consistent with evidence in vertebrates of increased firing rates in the nucleus raphé dorsalis, two- to fivefold, coupled with oralbuccal movements (Ribeiro-Do-Valle et al., 1989), and modulatory effects exerted by raphé neurons upon widespread areas of cerebral cortex. Comparative data suggest that these monoaminergic circuits may share similar adaptive value and were, thereby, conserved through evolution. A role of the nucleus raphé dorsalis in visceral components of behavioral expression strongly correlates with evidence in primates (Robinson and Mishkin, 1968) that stimulus-bound food intake behaviors are provoked from an area of midline thalamus equivalent to the serotonergic projection field in $\mathrm{n}$.Pvt identified here. These observations tie beautifully with the role of 5-HT-receptor subtypes in the regulation of food intake and the contribution of 5-HT agonists to postprandial satiety (see Jimerson et al., 1990, for review). Lastly, an equally heavy monoaminergic innervation of 
A.

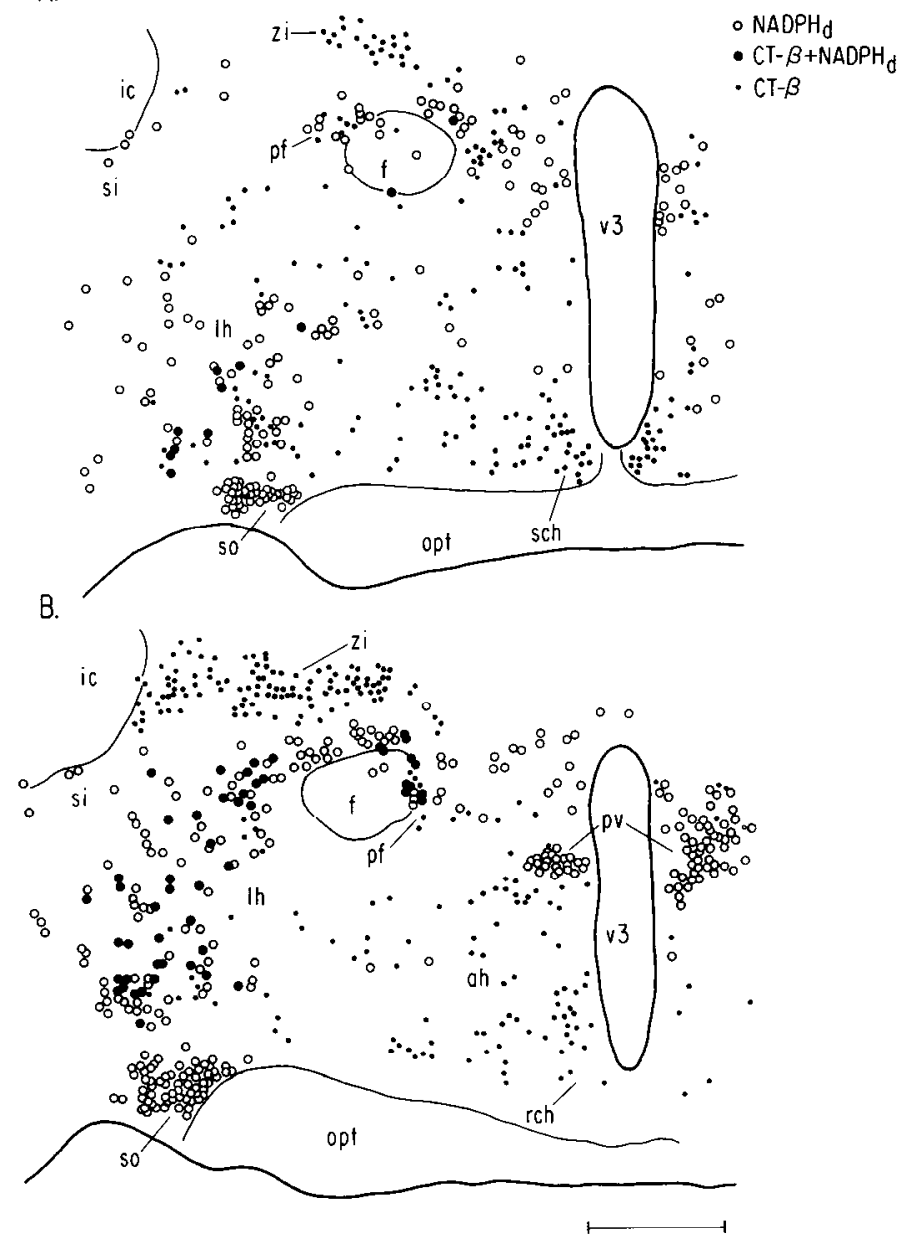

Figure 15. Camera lucida drawings show distributional patterns of CT-B-retrogradely labcled cells and NADPH-d-containing cells in the lateral hypothalamic area at the level of the optic chiasm $(A)$ and just caudally $(B)$. Injection site is shown in the inset of Figure 16 . Retrogradely labeled cells indicated by dots; NADPH-d-positive cells by open circles and dually labeled cells by solid circles. Scale bar, 500 $\mu \mathrm{m}$.

the n.Pvt and its principal target sites in frontal limbic cortex correlates with evidence in humans of a role of serotonin in mood disorders (Melzer, 1990), and the pathogenesis of suicidal behavior (Arango et al., 1990, 1993). Still to be determined is whether the midline thalamus contributes to the link between impaired 5-HT function and major depression in anorexia nervosa (Jimerson et al., 1990, for review).

\section{Afferents to the midline thalamus may generate NO}

Evidence was obtained that afferents to the midline thalamus contain the enzyme NADPH-d and thus may generate NO as a labile transcellular messenger. The $n$.Pvt and central medial midline-intralaminar nuclei were confirmed as major postsynaptic targets of potential afferent interaction with NO. Our anatomical data justify the following two principal conclusions.

Origins of ascending afferent projection to the midline thalamus may generate NO and are restricted to cell groups in the rostral lateral hypothalamic area and mesopontine tegmentum. In support are the following observations. (1) The enzyme NADPH-d was enriched within the neuropil of the midline thalamus in processes resembling terminals, confirming the ob- servations of Vincent and Kimura (1992). Our observations demonstrate that the field in the n.Pvt is well demarcated and significantly heavier than suggested by the description in the latter study, "A few weak or moderately stained medium-sized neurons and fibers were present, scattered in the n.Pvt." The enzyme was selectively localized in our material to discrete divisions of the midline-intralaminar complex characterized by a clear concentration gradient. A prominent plexus parcellated anterior as well as posterior divisions of the n.Pvt: a nucleus previously classified as epithalamic (Jones, 1985), and, recently, as a member of midline-intralaminar complex (Berendse and Groenewegen, 1991; Otake et al., 1993, 1994). The region of the nucleus enriched in NADPH-d was identical to the locus identified in our concomitant study as thalamocortical (Otake et al., 1994). The origins of this chemically identified plexus in the midline thalamus were localized in the mesopontine tegmentum to the laterodorsal tegmental nucleus, and in the forebrain to the lateral hypothalamic area, loci where NADPH-dstained cell bodies are heavily concentrated (Vincent and Kimura, 1992). A significant portion of the NADPH-d-stained processes may also arise, locally, from NADPH-d containing cell bodies identified within the $n$.Pvt and subjacent divisions of the midline-intralaminar complex; (2) Previous studies have attributed NADPH-d staining patterns in the CNS to neural networks that generate NO (Dawson et al, 1991). NADPH-d, involved in the reduction of tetrazolium salts to insoluble formazans, and NOS, which catalyzes the protein-kinase modulated conversion of arginine to NO and citrulline are thought to constitute properties of the same molecule. Both enzymes were correlated histochemically by comparable regional distributions in most arcas of the PNS and CNS (Bredt ct al., 1991; Dawson et al., 1991; Hope et al., 1991; Belai et al, 1992; Hassall et al., 1992). Our incubation times were comparable to those found previously to label the fraction of NADPH-d associated with the brain NOS isoenzyme. These parameters were critical since prolonged histochemical reaction times have produced, in some regions, widespread staining of cells in which NADPH-d may be associated with enzymes other than NOS (Hope et al., 1991; Hassall et al., 1992). Because NADPH-d is thought not to necessarily confer NOS-enzyme activity, also critical to our interpretation is evidence that fixation may destroy the non-NOS fraction. We should, here, emphasize that our material was well fixed, by transcardiac perfusion and postfixed for $2-3 \mathrm{hr}$ prior to staining for NADPH-d.

The n.Pvt is a major target of ascending noncholinergic projection. The aforementioned data suggest that the n.Pvt constitutes one of the principal targets in the midline-intralaminar complex of afferents presumed to generate NO. NO in the lateral geniculate body derives exclusively from neurons that cosynthesize ACh (Bickford et al., 1993). The following observations, however, indicate that the principal source of mesopontine afferent projection to the $n$.Pvt is noncholinergic. This conclusion is justified by two bits of evidence. (1) The n.Pvt, although containing a dense plexus of NADPH-d-positive processes was, by contrast, extremely sparsely labeled for ChAT. This observation confirms that of Ichikawa and Hirata (1986). In comparison to other areas of the thalamus, cholinoreceptors, and high affinity, choline-uptake sites as identified immunocytochemically or in radioligand binding studies appeared to us rather weakly labeled in the midline-intralaminar complex, as compared to the higher densities in neighboring areas of the diencephalon, for example, reticular and anterior 

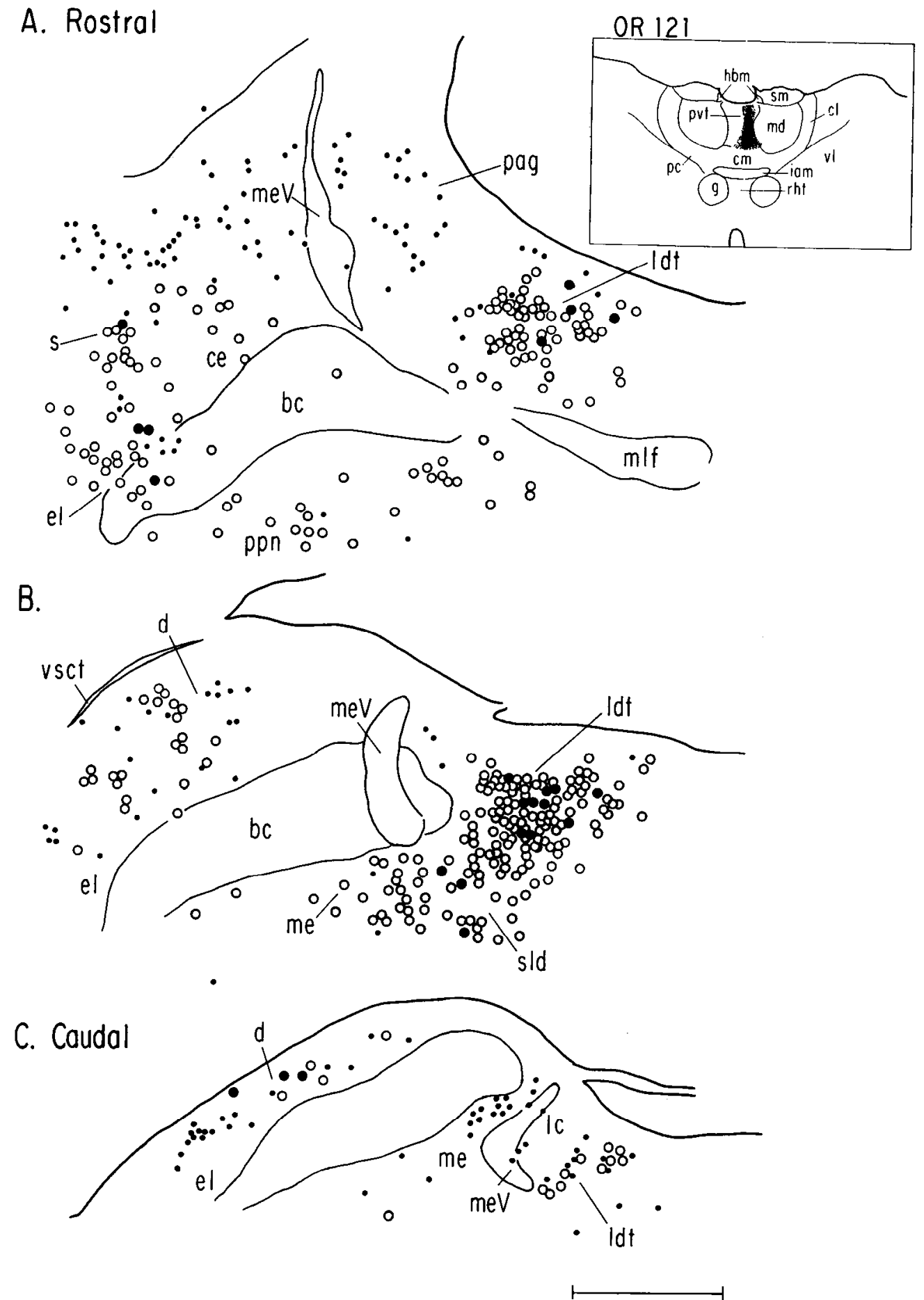

Figure 16. Camera lucida drawings show distributional patterns of retrogradely labeled cells and NADPH-dcontaining cells in the mesopontine tegmentum. Upper right inset shows a CT-B injection sitc. Retrogradely labeled cells are indicated by dots; NADPH-d-positive cells by open circles and dually labeled cells by solid circles. Scale bar, $500 \mu \mathrm{m}(770 \mu \mathrm{m}$ for inset).

thalamic nuclear groups (Clarke et al., 1985; Quirion, 1987; see Fig. $2 D$ of Swanson et al., 1987). The midline-intralaminar complex was also unlabeled by in situ RNA hybridization of an $\alpha$-subunit probe for the neural nicotinic-ACh receptor (Goldman et al., 1986). Although processes in the n.Pvt were previously recognized as histochemically positive for ACh-esterase (AchE) (Jacobowitz and Palkovits, 1974; see Fig. 16.15B of Jones, 1985), the discrepancy with our observation of sparse ChAT-immunoreactivity is additional support that the degradative enzyme is not a specific marker for cholinergic neurons. Evidence for AchE in noncholinergic nuclei, such as dopami- nergic neurons of the substantia nigra pars compacta (Butcher et al., 1975), is especially interesting and, perhaps, relevant to a heavy catecholaminergic innervation of the midline thalamus by the hypothalamus (see below). The above observations were confirmed by us, by a virtual absence of retrograde transport to brainstem cholinergic cell bodies from injection sites centered on the n.Pvt. The efficacy of our dual-labeling method was, moreover, verified by retrograde transport to cells stained for NADPH-d in areas of the forebrain and mesopontine tegmentum where cells containing ChAT or retrograde tracers formed separate populations. 
Our data, therefore, indicate that afferent projections from the subcortical forebrain and lower brainstem to the n.Pvt are predominantly noncholinergic. Perhaps related is evidence that a large number of nuclei which issue afferent projections to the n.Pvt, for example, dorsomedial and arcuate hypothalamic nuclei, are also intensely AchE-positive but devoid of ChAT. Prethalamic projection cells in diencephalic-dopaminergic areas may, therefore, account for part of the AchE-positive processes in the midline thalamus (Eckenstein and Sofroniew, 1983). NADPH-d in the n.Pvt, however, might be colocalized with other putative neuromodulators, for example, neuropeptides coexpressed in cells in the laterodorsal and pedunculopontine tegmental nuclei (Vincent et al., 1986).

\section{Concluding remarks}

The midline thalamus is incorporated within a neural network involved in generating organized behaviors (Papez, 1937; Hess, 1957; MacLean, 1973). In support is the remarkable specificity of midline thalamic connections (Otake et al., 1993, 1994) with nuclei implicated in affective processing of polysensory afferents and which mediate somatic and visceral components of behavioral expression (Kievet and Kuypers, 1975; Saper et al., 1979; Berk and Finkelstein, 1982; see LeDoux, 1987, for review). The midline intralaminar thalamus is a target of neurochemically -identified afferent projections which exert powerful modulatory effects on networks modifying electrocortical activity and behavior. Sources of chemically identified afferents to the dorsal division of the midline thalamus contribute to statedependent regulation of thalamocortical rhythms, and a remarkably large number (Otake et al., 1993, 1994) are antinociceptive and members of the brain reward network supporting high rates of intracerebral self-stimulation (Olds, 1962; Phillips, 1984; Velley, 1986; Ferssiwi et al., 1987). The functional significance of the dense monoaminergic and NADPH-d positive plexi in the $\mathrm{n}$. Pvt and striking spatial overlap with cholinergic processes in the central medial intralaminar nucleus is unknown. We can predict, based on our structural data, that interactions attributed to the mesopontine source of NO in the LGN (Pape and Mager, 1992; Bickford et al., 1993) may also apply to actions on nonspecific thalamosensory neurons in the midline-intralaminar complex.

We conclude that NO may act as a membrane-permeant transcellular signal in the nondiscriminative thalamus. Extensive interactions with classical neurotransmitters appear likely, based on striking overlap of processes expressing different synthetic monoaminergic and cholinergic enzymes. Presynaptic as well as postsynaptic interactions are possible based on physiological data implicating NO as an early retrograde messenger, facilitating long-term potentiation in hippocampus (O'Dell et al., 1991); as a cellular mediator in other sensory processing centers, such as the NTS (Harada et al., 1993) and autonomic nervous system, for example, the dorsal motor nucleus (Travagli and Gillis, 1994). Evidence that the identified neurons actually generate NO is supported by the coexpression of NADPH-d and NOS by cells in virtually all regions examined both in the PNS and CNS (Dawson et al. 1991). Moreover, NADPH-d staining in the nondiscriminative nuclei, particularly in the n.Pvt and central medial intralaminar nucleus, was remarkably well circumscribed and equivalent in concentration to that in the LGN where NO was recently shown to dampen oscillatory activities of thalamocortical neurons (Pape and Mager, 1992). The functional significance of the especially high density in n.Pvt is unknown, although a role in behavioral expression seems likely. Consistent with this hypothesis is the integration of n.Pvt in limbic circuitry. Principal targets of $n$.Pvt outflow include areas of frontal visceral cerebral cortex and archistriatum, nucleus accumbens and amygdala, involved in viscerosensory processing of olfactory and gustatory signals long recognized as critical to behavioral and goal-seeking behavior and classical conditioning (Mogenson et al., 1980; LeDoux, 1987, for revicws). An especially dramatic example underscoring a role of NO in addictive behavior are striking inductions of the intermediate-early gene c-fos, specifically within the n.Pvt and along its neural network by environmental cues previously paired with a drug of abuse, cocaine (Brown et al., 1992). Directly correlated is evidence that the integrity of cell bodies in the lateral hypothalamus, a key source of NO identified in the In.Pvt as shown here, is essential for intracranial self-stimulation of pontine gustatory thalamosensory relay neurons implicated in the brain-reward circuitry (Ferssiwi et al., 1987) and control of food and water intake (Anand and Brobeck, 1951).

Still unknown are the spheres of influence of membrane-permeant transcellular signals, independent of the constraints imposed by synaptic structure. The functional specificity of the effective site(s) of action is clearly dictated by the connectivity of the target neurons. Perhaps, such novel modes of transneuronal communication enable structurally segregated members of the diffuse thalamocortical projection system to act in concert as a single unified unit. It is hypothesized that NO may play an interactive role in sensory systems engaged in parallel distributed processing of signals influencing visceral reflex function and behavior

\section{Appendix}

\section{Abbreviations}

ah anterior hypothalamic nucleus

ap area postrema

arc arcuate hypothalamic nucleus

bc brachium conjunctivum

cc central canal

$\mathrm{ce}$

$\mathrm{cl}$ central subnucleus of the lateral parabrachial nucleus central lateral thalamic nucleus central medial thalamic nucleus cerebral peduncle

$\mathrm{cp}$

d

$\mathrm{dbc}$

dmx

dt

el

f

fr

g $\mathrm{gp}$ hbl dorsal subnucleus of the lateral parabrachial nucleus decussation of brachium conjunctivum

dorsal motor nucleus of the vagus

dorsal tegmental nucleus

external subnucleus of the lateral parabrachial nucleus fornix

fasciculus retroflexus gelatinosus thalamic nucleus globus pallidus

lateral habenular nucleus medial habenular nucleus interanteromedial thalamic nucleus internal capsule

locus ceruleus laterodorsal tegmental nucleus

lateral tegmental ficld interpeduncular nucleus lateral hypothalamic area lataral reticular nucleus medial nucleus of amygdala mediodorsal thalamic nucleus medial parabrachial nucleus mesencephalic trigeminal tract medial lemniscus medial longitudinal fasciculus mammillothalamic tract 
myn medial vestibular nucleus

nac nucleus ambiguus, compact formation

nal nucleus ambiguus, loose formation

nts nucleus tractus solitarii

opt optic tract

pag periaqueductal gray

pc paracentral thalamic nucleus

pcg pontine central gray

pe periventricular nucleus

pr perifonical nucleus

pg pontine gray

$\mathrm{ph} \quad$ posterior hypothalamic area

po posterior thalamic nucleus

pp prepositus hypoglossi nucleus

ppn pedunculopontine tegmental nucleus

pv paraventricular hypothalamic nucleus

pvt paraventricular thalamic nucleus

rch retrochiasmatic nucleus

rem reuniens thalamic nucleus, median part

ret reuniens thalamic nucleus

rht rhomboid thalamic nucleus

rme raphé medianus

rmg raphé magnus

rt reticular thalamic nucleus

$\mathrm{rtt}$ reticulotegmental nucleus of the pons

rvl rostral ventrolateral reticular nucleus

s superior subnucleus of the lateral parabrachial nucleus

sch suprachiasmatic nucleus

si substantia innominata

sm stria medullaris

ts solitary tract

v3 third ventricle

vl ventrolateral thalamic nucleus

$\mathrm{vm} \quad$ ventromedial thalamic nucleus

vpl ventral posterolateral thalamic nucleus

vpm ventral posteromedial thalamic nucleus

vsct ventral spinocerebellar tract

zi zona incerta

$\mathrm{V} \quad$ spinal trigeminal nucleus

$\mathrm{Vm} \quad$ motor trigeminal nucleus

VII facial nucleus

XII hypoglossal nucleus

\section{References}

Albe-Fessard D, Rougeul A (1958) Activité d'origine somesthésique évoquées sur le cortex non-spécifique du chat anesthésié au chloralose: rôle du centre médian du thalamus. Electroencephalogr Clin Neurophysiol 10:131-152.

Anand BK, Brobeck JR (1951) Hypothalamic control of food intake. Yale J Biol Med 24:123-140.

Arango V, Ernsberger P, Marzuk PM, Chen J-S, Tierney H, Stanley M, Reis DJ, Mann JJ (1990) Autoradiographic demonstration of increased serotonin $5-\mathrm{HT}_{2}$ and $\beta$-adrencrgic receptor binding sites in the brain of suicide victims. Arch Gen Psychiatry 47:1038-1047.

Arango V, Ernsberger P, Sved AF, Mann JJ (1993) Quantitative autoradiography of $\alpha 1$ - and $\alpha 2$-adrenergic receptors in the cerebral cortex of controls and suicide victims. Brain Res 630:271-282.

Armstrong DM, Ross CA, Pickel VM, Joh TH, Reis DJ (1982) Distribution of dopamine-, noradrenaline- and adrenaline-containing cell bodies in the rat medulla oblongata demonstrated by the immunocytochemical localization of catecholamine biosynthetic enzymes. J Comp Neurol 212:173-187.

Asanuma C (1989) Basal forebrain projections to the reticular thalamic nucleus in rat. Proc Natl Acad Sci USA 86:4746-4750.

Asanuma C (1992) Noradrenergic innervation of the thalamic reticular nucleus: a light and electron microscopic immunohistochemical study in rats. J Comp Neurol 319:299-311.

Asanuma C, Porter LL (1990) Light and electron microscopic evidence for a GABAergic projection from the caudal basal forebrain to the thalamic reticular nucleus in rats. J Comp Neurol 302:159-172.

Aston-Jones G, Bloom FE (1981) Activity of norepinephrine-containing locus coeruleus neurons in behaving rats anticipates fluctuations in the sleep-waking cycle. J Neurosci 1:876-886.

Azmitia E (1978) The serotonin-producing neurons of the midbrain median and dorsal raphe nuclei. In: Handbook of psychopharmacolgy, Vol 9 (Iversen LL, Iversen SD, Snyder SH, eds), pp 233-314. New York: Plenum.

Azmitia EC., Segal M (1978) An autoradiographic analysis of the differential ascending projections of the dorsal and median raphe nuclei in the rat. J Comp Neurol 179:641-667.

Belai A, Schmidt HHHW, Hoyle CHV, Hassall CJS, Saffrey MJ, Moss J, Förstermann U, Murad F, Burnstock G (1992) Colocalization of nitric oxide synthase and NADPH-diaphorase in the myenteric plexus of the rat gut. Neurosci Lett 143:60-64.

Beleslin DB, Stevanovic-Denic K (1986) A dose response study of aggressive behavioral effects of intracerebroventricular injections of carbachol in cats. Physiol Behav 36:75-78.

Bentivoglio M, Balercia G, Kruger L (1991) The specificity of the nonspecific thalamus: the midline nuclei. In: Progress in brain research, Vol 87 (Holstege G, ed), pp 53-80. Amsterdam: Elsevier.

Berendse HW, Groenewegen HJ (1991) Restricted termination fields of the midline and intralaminar thalamic nuclei in the rat. Neuroscience 42:73-102.

Berk ML, Finkelstein JA (1982) Efferent connections of the lateral hypothalamic area of the rat: an autoradiographic investigation. Brain Res Bull 8:511-526.

Bickford, ME, Günlük AE, Guido W, Sherman SM (1993) Evidence that cholinergic axons from the parabrachial region of the brainstem are the exclusive source of nitric oxide in the lateral geniculate nucleus of the cat. J Comp Neurol 334:410-430.

Bobillier P, Seguin S, Petitjean F, Salvert D, Touret M, Jouvet M (1976) The raphe nuclei of the cat brainstem: a topographical atlas of their efferent projections as revealed by autoradiography. Brain Res 13 : $449-486$.

Bonvallet M, Block V (1961) Bulbar control of cortical arousal. Science 133:1133-1134.

Bredt DS, Glatt CE, Hwang PM, Fotuhi M, Dawson TM, Snyder SH (1991) Nitric oxide synthase protein and mRNA are discretely localized in neuronal populations of the mammalian CNS together with NADPH diaphorase. Neuron 7:615-624.

Brown EE, Robertson GS, Fibiger HC (1992) Evidence for conditional neuronal activation following exposure to a cocaine-paired environment: role of forebrain limbic structures. J Neurosci 12:4112-4121.

Butcher LL, Talbot K, Bilezikjian L (1975) Acetylcholinesterase neurons in dopaminergic-containing regions of the brain. $J$ Neural Transm 37:127-153.

Clarke PBS, Schwartz RD, Paul SM, Pert CB, Pert A (1985) Nicotine binding in rat brain: autoradiographic comparison of $\left[{ }^{3} \mathrm{H}\right]$ acetylcholine, $\left[{ }^{3} \mathrm{H}\right]$ nicotine and $\left[{ }^{125} \mathrm{I}\right] \alpha$-bungarotoxin. J Neurosei 5:1307-1315.

Conrad LC, Leonard CM, Pfaff DW (1974) Connections of the median and dorsal raphe nuclei in the rat: an autoradiographic and degeneration study. J Com Neurol 56:179-206.

Consolazione A, Priestley JV, Cuello AC (1984) Serotonin-containing projections to the thalanus in the rat revealed by a horseradish peroxidase and peroxidase antiperoxidase double-staining technique. Brain Res 322:233-243.

Cornwall J, Phillipson OT (1988) Afferent projections to the dorsal thalamus of the rat as shown by retrograde lectin transport. II. The midline nuclei. Brain Res Bull 21:147-161.

Cropper EC, Eisenman JS, Azmitia EC (1984) An immunocytochemical study of the serotonergic innervation of the thalamus of the rat. J Comp Neurol 224:38-50.

Dafny N, Reyes-Vazquez C, Qiao JY (1990) Modification of nociceptively-identified neurons in thalamic parafascicularis by chemical stimulation with glutamate, morphine, serotonin and focal dorsal raphe electrical stimulation. Brain Res Bull 24:717-723.

Dawson TM, Bredt DS, Fotuhi M, Hwang PM, Snyder SH (1991) Nitric oxide synthase and neuronal NADPH diaphorase are identical in brain and peripheral tissues. Proc Natl Acad Sci USA 88:7797-7801.

Dell P, OIson R (1951) Projections thalamiques corticales et cerehelleuses des afferences viscerales vagales. C R Soc Biol (Paris) 145: 1084-1088.

Eckenstein F, Sofronicw MV (1983) Identification of central cholinergic neurons containing both choline acetyltransferase and acetylcholinesterase and of central neurons containing only acetylcholinesterase. J Neurosci 3:2286-2291.

Ferssiwi A, Cardo B, Velley L (1987) Electrical self-stimulation in the 
parabrachial area is depressed after ibotenic acid lesion of the lateral hypothalamus. Behav Brain Res 25:109-116.

Fields HL, Anderson SD (1978) Evidence that raphe-spinal neurons mediate opiate and midbrain stimulation-produced analgesias. Pain $5: 333-349$

Foote SL, Bloom FE, Aston-Jones G (1983) Nucleus locus coeruleus: new evidence of anatomical and physiological specificity. Physiol Rev 63:844-914.

Gebhart GF (1986) Modulatory effects of descending systems on spinal dorsal hom neurons. In: Spinal afferent processing (Yaksh TL, ed), pp 391-416. New York: Plenum.

Goldman D, Simmons D, Swanson L, Patrick J, Heinemann S (1986) Mapping of brain areas expressing RNA homologous to two different acetylcholine receptor $\alpha$-subunit cDNAs. Proc Natl Acad Sci USA 83:4076-4080.

Hallanger AE, Levey AI, Lee HJ, Rye DB, Wainer BH (1987) The origins of cholinergic and other subcortical afferents to the thalamus in the rat. J Comp Neurol 262:105-124.

Harada S, Tokunaga S, Momohara M, Masaki H, Tagawa T, Imaizumi $T$, Takeshita A (1993) Inhibition of nitric oxide formation in the nucleus tractus solitarius increases renal sympathetic nerve activity in rabbits. Circ Res 72:511-516.

Hassall CJS, Saffrey MJ, Belai A, Hoyle CHV, Moules EW, Moss J, Schmidt HHHW, Murad F, Förstermann U, Burnstock G (1992) Nitric oxide synthase immunoreactivity and NADPH-diaphorase in a subpopulation of intrinsic neurones of the guinea-pig heart. Neurosci Lett 143:65-68.

Herkenham M (1986) New perspectives on the organization and evolution of nonspecific thalamocortical projections. In: Cerebral cortex, Vol 5 (Jones EG, Peters A, eds), pp 403-445. New York: Plenum.

Hess WR (1957) The functional organization of the diencephalon (Hughes JR, ed). New York: Grune \& Stratton.

Hobson JA, McCarley RW, Wyzinski PW (1975) Sleep cycle oscillation: reciprocal discharge by two brain stem neuronal groups. Science $189: 55-58$.

Hökfelt T, Fuxe K, Goldstein M, Johansson O (1974) Immunohistochemical evidence for adrenaline neurons in the rat brain. Brain Res 66:235-251.

Hökfelt T, Johansson O, Goldstein M (1984a) Central catecholamine neurons as revealed by immunohistochemistry with special reference to adrenaline neurons. In: Handbook of chemical neuroanatomy, Vol 2 (Björklund A, Hökfelt T, eds), pp 157-276. Amsterdam: Elsevier.

Hökfelt T, Mårtensson R, Björklund A, Kleinau S, Goldstein M (1984b) Distributional map of tyrosine-hydroxylase-immunoreactive neurons in the rat brain. In: Handbook of chemical neuroanatomy, Vol 2 (Björklund A, Hökfelt T, eds), pp 277-379. Amsterdam: Elsevier.

Hope BT, Michael GJ, Knigge KM, Vincent SR (1991) Neuronal NADPH diaphorase is a nitiric oxide synthase. Proc Natl Acad Sci USA $88: 2811-2814$

Hunter J, Jasper HH (1949) Effects of thalamic stimulation in unanesthetized animals: the arrest reaction and petit mal-like seizures, activation patterns and generalized convulsions. Electroencephalogr Clin Neurophysiol 1:305-321.

Ichikawa T, Hirata Y (1986) Organization of choline acetyltransferasecontaining structures in the forebrain of the rat. J Neurosci 6:281292.

Jacobowitz DM, Palkovits M (1974) Topographic atlas of catecholamine and acetylcholinesterase-containing neurons in the rat brain. $\mathrm{J}$ Comp Neurol 157:13-28.

Jaeger CB, Ruggiero DA, Albert VR, Joh TH, Reis DJ (1984) Immunocytochemical localization of aromotic-L-amino acid decarboxylase. In: Handbook of chemical neuroanatomy, Vol 2 (Björklund A, Hökfelt T, eds), pp 387-408. Amsterdam: Elsevier.

Jimerson DC, Lesum MD, Hegg AP, Brewerton TD (1990) Serotonin in human eating disorders. Ann NY Acad Sci 600:532-544.

Jones BE (1978) Innervation of forebrain regions by medullary noradrenaline neurons, a biochemical study in cats with central tegmental tract lesions. Neurosci Lett 10:251-258.

Jones BE, Moore RY (1977) Ascending projections of the locus coeruleus in the rat. II. Autoradiographic study. Brain Res 127:23-53.

Jones BE, Yang T-Z (1985) The efferent projections from the reticular formation and the locus coeruleus studied by anterograde and retrograde axonal transport in the rat. J Comp Neurol 242:56 92.

Jones EG (1985) 'The thalamus. New York: Plenum.

Jouvet M (1972) The role of monoamines and acetylcholine containing neurons in the regulation of the sleep-wake cycle. Rev Physiol (Ergeb Physiol) 64:166-307.

Kievet J, Kuypers HGJM (1975) Basal forebrain and hypothalamic connections to the frontal and parietal cortex in the monkey. Science 187:660-662.

Koella WP (1977) Beta-blockers and sleep. In: Beta blockers and the central ncrvous systcm (Kiclholtz, ed), pp 174-183. Bern: Iluber.

LeDoux JE (1987) Emotion. In: Handbook of physiology, The nervous system, Vol V (Plum F, ed), pp 419-459. Bethesda, MD: American Physiological Society.

Lindvall O, Björklund A, Nobin A, Stenevi U (1974) The adrenergic innervation of the rat thalamus as revealed by the glyoxylic acid fluorescence method. J Comp Neurol 154:317-348.

Lindvall O, Bjorklund A, Skagerberg G (1984) Selective histochemical demonstration of dopamine terminal systems in rat di- and telencephalon: new evidence for dopaminergic innervation of hypothalamic neurosecretory nuclei. Brain Res 306:19-30.

Loewy AD, McKeller S, Saper CB (1979) Direct projections from the A5 catecholamine cell group to the intermediolateral cell column. Brain Res 174:196-200.

Loughlin SE, Foote SL, Bloom FE (1986) Efferent projections of nucleus locus coeruleus: topographic organization of cells of origin demonstrated by three-dimensional reconstruction. Neuroscience 18: 291-306.

Macchi G, Bentivoglio M (1986) The thalamic intralaminar nuclei and the cerebral cortex. In: Cerebral cortex, Vol 5 (Jones EG, Peters A, eds), pp 355-401. New York: Plenum.

MacLean PD (1973) A triune concept of the brain and behaviour. In: The Clarence M. Ilincks memorial lectures (Boag TJ, Campbell D, eds). Toronto: University of Toronto/Ontario Mental Health Foundation.

Meltzer HY (1990) Role of serotonin in depression. Ann NY Acad Sci 600:486-500

Mogenson GJ, Jones DL, Yim CY (1980) From motivation to action: functional interface between the limbic system and the motor system. Prog Neurobiol 14:69-97.

Montero VM (1987) Localization of $\gamma$-aminobutyric acid (GABA) in type 3 cells and demonstration of their source to $F 2$ terminals in the cat lateral geniculate nucleus: a Golgi-electron-microscopic GABAimmunocytochemical study. J Comp Neurol 254:228-245.

Montero VM, Zempel J (1985) Evidence for two types of GABAcontaining interneurons in the A-laminae of the cat lateral geniculate nucleus: a double-label HRP and GABA-immunocytochemical study. Exp Brain Res 60:603-609.

Morison RS, Dempsey EW (1942) A study of thalamo-cortical relations. Am J Physiol 135:281-292.

O'Dell TJ, Hawkins RD, Kandel ER, Arancio O (1991) Tests of the roles of two diffusable substrates in long-term potentiation: evidence for nitric oxide as a possible early retrograde messenger. Proc Natl Acad Sci USA 88:11285-11289.

Olds J (1962) Hypothalamic substrates of reward. Physiol Rev 42:554604.

Olschowka JA, Molliver MG, Grzanna R, Rice FL, Coyle JT (1981) Ultrastructural demonstration of noradrenergic synapses in the rat central nervous system by dopamine $\beta$-hydroxyrase immunocytochemistry. J Histochem Cytochem 29:271-280.

Otake K, Anwar M, Reis DJ, Nakamura Y, Ruggiero DA (1993) Structural basis for visceral sensory and midline thalamic integration. Soc Neurosci Abstr 19:434.

Otake K, Reis DJ, Ruggiero DA (1994) Afferents to the midline thalamus issue collaterals to the nucleus tractus solitarii: an anatomical basis for thalamic and visceral reflex integration. J Neurosci 14:56945707.

Papadopoulos GC Parnavelas JG (1990) Distribution and synaptic organization of serotonergic and noradrenergic axons in the lateral geniculate nucleus of the rat. J Comp Neurol 294:345-355.

Pape H-C, Mager R (1992) Nitric oxide controls oscillatory activity in thalamocortical neurons. Neuron 9:441-448.

Papez JW (1937) A proposed mechanism of emotion. Arch Neurol Psychiatry 38:725-743.

Phillips AG (1984) Brain reward circuitry: a case for separate systems. Brain Res Bull 12:195-201.

Prieto-Gomez B, Dafny N, Reyes-Vazquez C (1989) Dorsal raphe stimulation, 5-HT and morphine microiontophoresis effects on noxious 
and non-noxious identified neurons in the medial thalamus of the rat Brain Res Bull 22:937-943.

Purpura DP (1972) Intracellular studies of synaptic organizations in the mammalian brain. In: Structure and function of synapses (Pappas GD, Purpura DP, eds), pp 257-302. New York: Raven.

Purpura DP, Frigyesi TL, McMurtry JC, Scarff T (1966) Synaptic mechanisms in thalamic regulation of cerebello-cortical projection activity In: Thalamus (Purpura DP, Yahr MD, eds), pp 153-170. New York: Columbia UP.

Quirion R (1987) Characterization and autoradiographic distribution of hemicholinium-3 high-affinity choline uptake sites in mammalian brain. Synapse 1:293-303.

Ribeiro-Do-Valle LE, Fornal CA, Litto WJ, Jacobs BL (1989) Serotonergic dorsal raphe unit activity related to feeding/grooming behaviors in cats. Soc Neurosci Abstr 15:1283.

Ricardo JA, Koh ET (1978) Anatomical evidence of direct projections from the nucleus of the solitary tract to the hypothalamus, amygdala, and other forebrain structures in the rat. Brain Res 153:1-26.

Robertson RT, Thompson RF (1973) Effects of subcortical ablations on cortical association responses in the cat. Physiol Behav 10:245252.

Robinson BW, Mishkin M (1968) Alimentary responses to forebrain stimulation in monkeys. Exp Brain Res 4:330-366.

Rosen SC, Weiss KR, Goldstein RS, Kupfermann I (1989) The role of a modulatory neuron in feeding and satiation in Aplysia: effects of lesioning of the serotonergic metacerebral cells. J Neurosci 9:15621578.

Ross CA, Ruggiero DA, Joh TH, Park DH, Reis DJ (1984) Rostral ventrolateral medulla: selective projections to the thoracic autonomic cell column from the region containing $\mathrm{C} 1$ adrenaline neurons. $\mathrm{J}$ Comp Neurol 228:168-184.

Ruggiero DA, Ross CA, Kumada M, Reis DJ (1982) Reevaluation of projections from the mesencephalic trigeminal nucleus to the medulla and spinal cord: new projections. A combined retrograde and anterograde horseradish pcroxidasc study. J Comp Neurol 206:278-292.

Ruggiero DA, Baker H, Joh TH, Reis DJ (1984) Distribution of catecholamine neurons in the hypothalamus and preoptic region of mouse. J Comp Neurol 223:556-582.

Ruggiero DA, Ross CA, Anwar M, Park DH, Joh TH, Reis DJ (1985) Distribution of neurons containing phenylethanolamine $N$-methyltransferase in medulla and hypothalamus of rat. J Comp Neurol 239:127-154.

Ruggiero DA, Cravo SL, Arango V, Reis DJ (1989) Central control of the circulation by the rostral ventrolateral reticular nucleus: anatomical substrates. In: Progress in brain research, Vol 81 (Ciriello J, Caverson MM, Polosa C, eds), pp 49-79. Amsterdam: Elsevier.

Ruggiero DA, Pickel VM, Milner TA, Anwar M, Otake K, Mtui EP, Park D (1994) Viscerosensory processing in nucleus tractus solitarii: structural and neurochemical substrates. In: Nucleus of the solitary tract (Barraco RA, ed), pp 3-34. Boca Raton, FL: CRC.

Saper CB, Swanson LW, Cowan WM (1979) An autoradiographic study of the efferent connections of the lateral hypothalamic area in the rat. J Comp Neurol 183:689-706.

Sim LJ, Joseph SA (1992) Serotonin and substance $P$ afferents to parafascicular and central medial nuclei. Peptides 13:171-176.

Steinbusch HWM (1981) Distribution of serotonin-immunoreactivity in the central nervous system of the rat- cell bodies and terminals. Neuroscience 6:557-618.

Steriade M, McCarley RW (1990) Brainstem control of wakefulness and sleep. New York: Plenum.

Steriade M, Llinás RR (1988) The functional states of the thalamus and the associated neuronal interplay. Physiol Rev 68:649-742.

Steriade M, Parent A, Paré D, Smith Y (1987) Cholinergic and noncholinergic neurons of cat basal forebrain project to reticular and mediodorsal thalamic nuclei. Brain Res 408:373-376.

Stornetta R, Ruggiero DA, Keis DJ (1987) Spinal projections to catecholamine-containing nuclei in the brainstem of the rats. Anat Rec 218:131A.

Swanson LW (1982) The projections of the ventral tegmental area and adjacent regions: a combined fluorescence retrograde tracer and immunofluorescence study in the rat. Brain Res Bull 9:321-353.

Swanson LW, Hartman BK (1975) The central adrenergic system. An immunoffuorescence study of the location of cell bodies and their efferent connections in the rat utilizing dopamine- $\beta$-hydroxylase as a marker. J Comp Neurol 163:467-506.

Swanson LW, Simmons DM, Whiting PJ, Lindstrom J (1987) Immunohistochemical localization of neuronal nicotinic receptors in the rodent central nervous system. J Neurosci 7:3334-3342.

Takada M, Campbell KJ, Moriizumi T, Hattori T (1990) On origin of the dopaminergic innervation of the paraventricular thalamic nucleus. Neurosci Lett 115:33-36.

Travagli RA, Gillis RA (1994) Nitric oxide-mediated excitatory effect on neurons of dorsal motor nucleus of vagus. Am J Physiol 266: in press.

Van Bockstaelle EJ, Pickel VM (1993) Ultrastructure of serotonin-immunoreactive terminals in the core and shell of the rat nucleus accumbens: cellular substrate for interactions with catecholamine afferents. J Comp Neurol 334:603-617.

Velley L (1986) Effects of ibotenic acid lesion in the basal forebrain on electrical self-stimulation in the middle part of the lateral hypothalamus. Behav Brain Res 20:303-311.

Vincent SR, Kimura H (1992) Histochemical mapping of nitric oxide synthase in the rat brain. Neuroscience 46:755-784.

Vincent SR, Satoh K, Armstrong DM, Fibiger HC (1983) NADPHdiaphorase: a selective histochemical marker for the cholinergic neurons of the pontine reticular formation. Neurosci Lett 43:31-36.

Vincent SR, Satoh K, Armstrong DM, Panula P, Vale W, Fibiger HC (1986) Neuropeptides and NADPH-diaphorase activity in the ascending cholinergic reticular system of the rat. Neuroscience 17:167182.

Weiss KR, Cohen JL, Kupfermann I (1978) Modulatory control of buccal musculature by a serotonergic neuron (metacerebral cell) in Aplysia. J Neurophysiol 41:181-203.

Westlund KN, Bowker RM, Ziegler M, Coulter JD (1981) Origins of spinal noradrenergic pathways demonstrated by retrograde transport of antibody to dopamine- $\beta$-hydroxylase. Neurosci Lett 25:243-249.

Westlund KN, Sorkin LS, Ferrington DG, Carlton SM, Willcockson HH, Willis WD (1990) Serotonergic and noradrenergic projections to the ventral posterolateral nucleus of the monkey thalamus. J Comp Neurol 295:197-207.

Willis WD Jr (1986) Ascending somatosensory systems. In: Spinal afferent processing (Yaksh TL, ed), pp 243-274. New York: Plenum. 